\title{
DEVELOPMENT OF MULTIPARTICULATE FORMULATION AND EVALUATION OF COLON TARGETED DRUG DELIVERY SYSTEM OF CIPROFLOXACIN: IN VIVO STUDY WITH INDUCED COLITIS MODEL IN RATS
}

\author{
NALANDA TULSIRAM RANGARI ${ }^{1 *}$, PRASHANT K PURANIK ${ }^{2}$
}

\begin{abstract}
${ }^{1}$ Department of Pharmaceutics, Swami Ramanand Teerth Marathwada University, Nanded, Maharashtra, India. ${ }^{2}$ Department of
\end{abstract} Pharmaceutical Sciences, RTM Nagpur University, Maharashtra, India. Email: nalanda.rangari@gmail.com

Received: 11 August 2016, Revised and Accepted: 21 September 2016

\section{ABSTRACT}

Objective: The objective of this research work was to develop a multiparticulate containing chitosan and guar gum for the treatment of ulcerative colitis.

Method: Method for the formulation of multiparticulate was done by extrusion-spheronization method using Eudragit L-100 and Eudragit S-100 as a coating solution and ciprofloxacin as a model drug.

Result: Result from preliminary trial batches was previously assessed for physicochemical characterization, in vitro release, ex vivo mucoadhesion study, swelling studies, and in vivo evaluation and showed that the formulations appeared to be a good candidate to deliver the drug to the colon. Box-Behnken design was used to statistically optimize the formulation parameters and evaluate the main effects, interaction effects, and quadratic effects of the process parameters of enteric-coated multiparticulate on drug polymer ratio and coat composition. In this work, the effectiveness of optimized batch (C4) in the treatment of inflammatory bowel disease was evaluated. Experimentally, colitis was induced by rectal instillation of 2, 4, 6, trinitrobenzene sulfonic acid into male Wistar rats. The histological evaluations were done as inflammatory indices. In vivo gamma scintigraphy studies of multiparticulate without a drug demonstrate degradation of multiparticulate whenever they reach colon.

Conclusion: The conclusion from results of studies such as gamma scintigraphy and histological study of optimized formulation (C4) clearly indicates that there is a great potential in delivery of ciprofloxacin to the colonic region. The animals treated with ciprofloxacin (C4) formulation had an improvement in pathology and may be useful for the treatment of inflammatory bowel disease.

Keywords: Chitosan, Guar gum, Ciprofloxacin, Gamma scintigraphy, Histology, Ulcerative colitis, Box-Behnken design.

(C) 2017 The Authors. Published by Innovare Academic Sciences Pvt Ltd. This is an open access article under the CC BY license (http://creativecommons. org/licenses/by/4. 0/) DOI: http://dx.doi.org/10.22159/ajpcr.2017.v10i1.14634

\section{INTRODUCTION}

The colon is an ideal site for protein and peptide absorption. Acidic and enzymatic degradations are major obstacles in the oral administration of peptide drugs, but by targeting to the colon, the proteolysis can be minimized. Colon targeting had application in several therapeutic areas such as colon cancer, ulcerative colitis, irritable bowel syndrome, or the administration of drugs that are adversely affected by the upper gastrointestinal tract (GIT). There has been considerable research in the design of colonic delivery systems and targeting has been achieved by several ways. The primary approaches to the colonic delivery of the drugs included prodrugs, coating with $\mathrm{pH}$-sensitive and timedependent polymers. Eudragit L-100 and Eudragit S-100 are used as an enteric-coating material to keep the multiparticulates intact and not to release the drug in stomach and or upper intestine. Natural polysaccharides such as pectin, chitosan, xylan, and guar gum are not digested in the human stomach or small intestine but are degraded in the colon by resident bacteria. Chitosan is a cationic natural copolymer of glucosamine, obtained from the deacetylation of chitin, which is the second most abundant polysaccharide after cellulose in the world. It has been widely used in several pharmaceutical formulations as controlled release carrier systems such as beads, gels, films, sponges, and multiparticulates for its many unique properties such as low toxicity, biocompatibility, and biodegradability chitin is a polysaccharide composed of $\beta-(1-4)$ linked N-acetyl-D-glucosamine unit. Chitosan is a weak base and is insoluble in water and organic solvents; however, it is soluble in dilute aqueous acidic solution $(\mathrm{pH}<6.5)$, which can convert the glucosamine unit to R-NH+ 3. In pharmaceutical formulations, chitosan is used as a vehicle for directly compressed tablets disintegrating, binding, and granulating agent [1-3].
Ciprofloxacin is a quinolone carboxylic acid derivative with an extensive antibacterial spectrum of activity. Ciprofloxacin is an antibiotic useful for the treatment of a number of bacterial infections. It is a secondgeneration fluoroquinolone. Ciprofloxacin and other fluoroquinolones are valued for this broad spectrum of activity, excellent tissue penetration, and for their availability in both oral and intravenous formulations. The absolute bioavailability is approximately $70 \%$ with no substantial loss by first pass metabolism. The drug has been shown to be active in most strains of the following microorganisms both in vitro and in clinical infections: Aerobic Gram-positive microorganisms - Enterococcus faecalis, Streptococcus pneumonia, Streptococcus pyrogenes, Staphylococcus saprophyticus, and Staphylococcus aureus; aerobic Gram-negative microorganisms - Enterobacter cloacae, Escherichia coli, Pseudomonas aeruginosa, Salmonella typhi, Klebsiella pneumonia, Neisseria gonorrhoeae, and Shigella sonnei.

The rational of present investigation was to target the enteric-coated multiparticulate of ciprofloxacin to colon for the successful treatment of ulcerative colitis induced by rectal instillation of $2,4,6$, trinitrobenzene sulfonic acid into male Wistar rats. The novelty behind the formulation was degradation of multiparticulate whenever they reach the colon which was investigated by in vivo gamma scintigraphy studies of multiparticulate without drug.

\section{MATERIALS AND METHODS}

\section{Materials}

Chitosan of medium molecular weight, ciprofloxacin, and guar gum was obtained from Space Lab (Nasik, Maharashtra, India). 2, 4, 6, trinitrobenzene sulfonic acid was purchased from Vishal Chem 
(Mumbai, Maharashtra, India). Eudragit L-100 and Eudragit S-100 were obtained as a gift sample from Concept Pharmaceutical (Aurangabad, Maharashtra, India).

\section{Preparation of multiparticulate of ciprofloxacin}

The multiparticulate of ciprofloxacin was prepared using the extrusionspheronization technique (RIMEK, Kalweka HD410AC, Gujarat, India). Briefly, chitosan and guar gum were first mixed using a laboratory blender (LB100 Laboratory Blender; REMI, Mumbai, India) for 10 minutes, and deionized water was added with further mixing (15 minutes) for the production of wet mass. The wet mass was extruded with an extruder (sieve opening $1 \mathrm{~mm}$; screen thickness $3.25 \mathrm{~mm}$; $15 \mathrm{rpm}$; extrudate cut off at a length of approximately $2-3 \mathrm{~mm}$ ) and spheronization of the extrudate in a spheronizer (spheronization speed $2200 \mathrm{rpm}$; spheronization time about 5 minutes). Multiparticulate in the size fraction 1.1-1.4 mm (N75\% yield in this size range) was used in the subsequent studies. The resultan multiparticulate was dried in a fluidized bed dryer at $30^{\circ} \mathrm{C}$ until the loss on drying, was $<2.5$ wt\% (Labultima, LU222 Advanced, Mumbai, India) Table 1 shows trial batches $[4,5]$.

\section{Coating of multiparticulate}

The enteric coating was done using conventional coating pan. $10 \%$ and $15 \%(w / w)$ solutions of polymethacrylates (Eudragit L100 and Eudragit S100) were prepared in isopropyl alcohol:water (9:1) mixture. The ratio of Eudragit S100:Eudragit L100 was 1:1; the enteric coating was done using conventional coating pan, and solutions of polymethacrylates were prepared in isopropyl alcohol:water (9:1) mixture. The ratio of Eudragit S100:Eudragit L100 was 1:1. The solution was plasticized with castor oil (20\%, w/w, with respect to dry polymer), titanium dioxide $(0.05 \% \mathrm{w} / \mathrm{v})$, and then, talc was added as glidant $(5 \%, \mathrm{w} / \mathrm{w}$, related to dry polymer). The enteric-coating dispersion was passed through a

Table 1: Preliminary trial batches of multiparticulate

\begin{tabular}{lll}
\hline $\begin{array}{l}\text { Batch code for } \\
\text { ciprofloxacin }\end{array}$ & $\begin{array}{l}\text { Drug:Polymer ratio } \\
\text { (wt/wt) }\end{array}$ & $\begin{array}{l}\text { Polymer ratio } \\
\text { (CH:GG) wt/wt }\end{array}$ \\
\hline C1a & $1: 1$ & $1: 1$ \\
C2a & $1: 1$ & $1: 1.5$ \\
C3a & $1: 1$ & $1.5: 1$ \\
C4a & $1: 1$ & $1: 2$ \\
C5a & $1: 1$ & $2: 1$ \\
C1b & $1: 1$ & $1: 1$ \\
C2b & $1: 1$ & $1: 1.5$ \\
C3b & $1: 1$ & $1.5: 1$ \\
C4b & $1: 1$ & $1: 2$ \\
C5b & $1: 1$ & $2: 1$ \\
\hline
\end{tabular}

Coat composition: $a=10, b=15 \%$
$0.3 \mathrm{~mm}$ sieve before use. Throughout the coating process, the coating dispersion was stirred using a magnetic stirrer. The parameters of the film-coating process were as follows: Pan rotating speed $20 \mathrm{rpm}$; atomizing air pressure $2 \mathrm{bar}$; inlet air temperature $60-70^{\circ} \mathrm{C}$; outlet air temperature $35-40^{\circ} \mathrm{C}$; multiparticulate bed temperature $38^{\circ} \mathrm{C}$; the coating solution was applied through a $1.1 \mathrm{~mm}$ spray nozzle. The film-coated multiparticulate was not removed from the pan until the complete weight gain was achieved. All the multiparticulate was stored in a vacuum desiccator at room temperature until used. A series of coated products with different film thickness was produced, quantified by the percentage total weight gain, by varying the amount of coating solutions sprayed.

\section{Experimental design for optimization}

Response surface methodology (RSM) is a widely practiced approach in the development and optimization of drug delivery devices. Based on the principle of design of experiments, the methodology encompasses the use of various types of experimental designs, generation of polynomial equations, and mapping of the response over the experimental domain to determine the optimum processing variables [6]. The technique requires minimum experimentation and time, thus proving to be far more effective and cost-effective than the conventional methods of formulating dosage forms. Box-Behnken design was used to statistically optimize the formulation parameters and evaluate the main effects, interaction effects, and quadratic effects of the process parameters of enteric-coated multiparticulate on drug polymer ratio and coat composition. A 3-factor, 3-level design was used to explore the quadratic and linear response surfaces using Design Expert Software (Version 9.0.1, Stat-Ease Inc., and Minneapolis, MN). Statistical validity of the polynomials was established on the basis of analysis of variance (ANOVA) provision in the Design Expert Software Level of significance was considered at $p<0.05$. The best-fitting mathematical model was selected based on the comparison of several statistical parameters, including the coefficient of variation (CV), the multiple correlation coefficient $\left(\mathrm{R}^{2}\right)$, the adjusted multiple correlation coefficient (adjusted $\mathrm{R}^{2}$ ), and the predicted residual sum of squares (PRESS), provided by the software. PRESS indicates how well the model fits the data, and for the chosen model, it should be small relative to the other models under consideration. The 3D response surface graphs and the 2D contour plots as generated by the Design Expert Software. These plots are very useful to see interaction effects of the factors on responses. Experimental design was done for optimization of polymer and optimization of coat composition (Eudragit S and L 100). Box-Behnken design was applied in the present study by considering chitosan, guar gum, and coat composition (Eudragit S and L 100) as independent variables and entrapment efficiency, mucoadhesion, \% drug release at $9,12,18$, and $24 \mathrm{hr}$ as dependent variables (Table 2).

Table 2: Factorial batches of ciprofloxacin

\begin{tabular}{|c|c|c|c|c|c|c|}
\hline Batch code & Variable level A & Variable level B & Variable level C & Chitosan (mg) & Guar gum (mg) & Coat composition (\%) \\
\hline $\mathrm{C} 1$ & 1 & -1 & 0 & 170 & 80 & 12.5 \\
\hline $\mathrm{C} 2$ & 1 & 1 & 0 & 170 & 170 & 12.5 \\
\hline $\mathrm{C} 3$ & 0 & 1 & -1 & 130 & 170 & 10 \\
\hline $\mathrm{C} 4$ & 1 & 0 & -1 & 170 & 130 & 10 \\
\hline $\mathrm{C} 5$ & 0 & 0 & 0 & 130 & 130 & 12.5 \\
\hline C6 & 0 & 0 & 0 & 130 & 130 & 12.5 \\
\hline $\mathrm{C} 7$ & 1 & 0 & 1 & 170 & 130 & 15 \\
\hline $\mathrm{C} 9$ & 0 & 0 & 0 & 130 & 130 & 12.5 \\
\hline C10 & 0 & 0 & 0 & 130 & 130 & 12.5 \\
\hline C11 & -1 & 1 & 0 & 80 & 170 & 12.5 \\
\hline C12 & 0 & -1 & 1 & 130 & 80 & 15 \\
\hline C13 & 0 & 1 & 1 & 130 & 170 & 15 \\
\hline C14 & 0 & 0 & 0 & 130 & 130 & 12.5 \\
\hline C15 & -1 & 0 & -1 & 80 & 130 & 10 \\
\hline C16 & -1 & -1 & 0 & 80 & 80 & 12.5 \\
\hline
\end{tabular}

Variable level: Low (-1), Medium (0), High (1) 
Table 2 shows the different variables and its levels used in the optimization design. Using these variables at different three levels, the trials were designed.

\section{Evaluation of multiparticulate \\ Micromeritics studies of multiparticulates}

The multiparticulates were characterized by their micromeritics properties such as particle size, bulk density, tapped density, Carr's compressibility index, Hausner ratio, and flow property.

\section{Swelling studies of multiparticulates}

A known weight $(100 \mathrm{mg}$ ) of various multiparticulates without drug was placed in phosphate buffer, $\mathrm{pH} 7.4$, and allowed to swell for the required period at $37 \pm 0.5^{\circ} \mathrm{C}$ using the USP dissolution apparatus with the dissolution basket assembly at $100 \mathrm{rpm}$. The multiparticulate particles were periodically removed blotted with filter paper and their changes in weight were measured during the swelling until equilibrium was attained. Finally, the weight of the swollen multiparticulate particles was recorded after a time period of $4 \mathrm{hrs}$, and the swelling ratio (SR) was then calculated from the formula:

$\mathrm{SR}=\left(\mathrm{W}_{\mathrm{e}}-\mathrm{W}_{0}\right) / \mathrm{W}_{0}$

Where, $\mathrm{W}_{0}$ "is the initial weight of the dry multiparticulate" and $\mathrm{W}_{\mathrm{e}}$ "is the weight of the swollen multiparticulate at equilibrium swelling" in the media. Each experiment was repeated three times, and the average value/standard deviation (SD) was taken as the SR value.

\section{Percentage yield (i.e. recovery) of multiparticulates formed}

The percentage yield of multiparticulate was determined by weighing after drying. The measured weight of prepared multiparticulates was divided by the total amount of all the nonvolatile components used for the preparation of the multiparticulates, which gave the total percentage yield of multiparticulates.

$\%$ Yield=(Actual weight of product/Total weight of excipient and drug) $\times 100$

\section{Drug content determination}

Multiparticulates equivalent to $250 \mathrm{mg}$ of the drug ciprofloxacin were taken for evaluation. The amount of drug entrapped was estimated by crushing the multiparticulates and extracting in $100 \mathrm{ml}$ methanol. After $24 \mathrm{hr}$, the extract was transferred to a $100 \mathrm{ml}$ volumetric flask and the volume was made up using methanol. The solution was filtered and the absorbance was measured after suitable dilution spectrophotometrically at $281 \mathrm{~nm}$ against methanol as a blank.

The amount of drug entrapped in the multiparticulates was calculated by the following formula:

$\%$ Drug entrapment $=\frac{\text { Calculated drug concentration }}{\text { Theoretical drug concentration }} \times 100$

Placebo multiparticulates were used as reference.

\section{Ex vivo mucoadhesion study}

The mucoadhesive property of the multiparticulate is evaluated on goat's intestinal mucosa by using phosphate buffer, as per monograph. Weighed microspheres were spread onto wet rinsed tissue specimen, and immediately thereafter, the slides are hung onto the arm of a USP tablet disintegrating test machine with suitable support at $37^{\circ} \mathrm{C}$. The weight of microspheres leached out at different intervals is measured. The $\%$ mucoadhesion is calculated by the following equation:

$\%$ Mucoadhesion $=\mathrm{W}_{\mathrm{a}}-\mathrm{W}_{1} / \mathrm{W}_{\mathrm{a}} \times 100$

Where, $\mathrm{W}_{\mathrm{a}}$ is the weight of multiparticulate applied, and $\mathrm{W}_{1}$ is the weight of multiparticulate leached out.
Dissolution test (in vitro drug release) of multiparticulates

In vitro dissolution test was conducted in USP 2 apparatus at $50 \mathrm{rpm}$ and a temperature of $37 \pm 0.5^{\circ} \mathrm{C}$. Sampling was done at predetermined time intervals and the same were estimated for drug content after suitable dilution using double beam UV-VIS spectrophotometer. Initial drug release studies were conducted in $900 \mathrm{ml}$ of $0.1 \mathrm{~N} \mathrm{HCl}$ for $2 \mathrm{hrs}$ followed by $900 \mathrm{ml}$ of 6.8 potassium phosphate buffer solution for next 3 hrs. Then, $900 \mathrm{ml}$ of 7.4 potassium phosphate buffer solution for rest of the time. Samples were filtered and assayed by ultraviolet spectrophotometry at $281 \mathrm{~nm}$. The concentration of each sample was determined from a predetermined calibration curve for ciprofloxacin.

\section{Optimization}

On the basis of evaluation parameters such as entrapment efficiency, percent yield, swelling studies, ex vivo mucoadhesion, and dissolution characteristics of the factorial batches of ciprofloxacin, which has shown the best results were optimized and selected for formulation of final dosage form (capsule) and advanced studies such as X-ray diffraction (XRD), differential scanning colorimeter (DSC), scanning electron microscopy (SEM), in vivo studies (Gamma scintigraphy), and histopathological evaluation was performed.

\section{Advanced studies on optimized batch of multiparticulates} XRD study

XRD measurements were made using Make: BRUKER, Germany, Model: D8 Advance, Source: $2.2 \mathrm{KW}$ Cu Anode, Dermic X-ray tube, Detector: Lynux Eye Detector, Beta Filter: Ni Filter Sample Holder: Zero Background and PMMA. The X-ray generator was operated at $40 \mathrm{kV}$ and $30 \mathrm{~mA}$, using the $\mathrm{Cu} \mathrm{K}$ line at $1.540600 \AA$ as the radiation source.

Each powdered specimen was packed in a specimen holder made of glass. In setting up the specimen and apparatus, coplanarity of the specimen surface with the specimen holder surface and the setting of the specimen holder at the position of symmetric reflection geometry were ensured. The powders were passed through a 100 mesh sieve and were placed into the sample holder by the side drift technique. The holder consisted of a central cavity. To prepare a sample for analysis, a glass slide was clipped to the top face of the sample holder so as to form a wall. The powder sample was filled into the holder, gently tapped and used for XRD measurement. $10 \mathrm{mg}$ of each sample was scanned at $25^{\circ} \mathrm{C}$ from $10-70^{\circ}$ and in step size of 0.019724 and count time of 46.5 seconds, using an automatic divergence slit assembly and a proportional detector. Relative intensities were read from the strip charts and corrected to fixed slit values.

\section{DSC studies of optimized multiparticulates}

Thermogram of samples was obtained by a Perkin-Elmer DSC. Samples of $10 \mathrm{mg}$ were accurately weighed into aluminum pans and then hermetically sealed with aluminum lids. The thermogram of samples was obtained at a scanning rate of $10^{\circ} \mathrm{C} /$ minutes over a temperature range of $40-390^{\circ} \mathrm{C}$.

\section{Morphological study using SEM}

The surface topography of the coated (optimized) multiparticulate examined under an FEI-Philips XL-30 Analytical Electron Microscope (IIT, Pawai). The sample was loaded on copper sample holder and sputter coated with platinum.

\section{In vivo gamma scintigraphy study}

The experiment was conducted in the laboratory of "Spect Lab Nuclear Medicine," Pune. The study reported here adheres to the principle of laboratory animal care and was approved by the Institutional Ethical Committee permitted by the IAEC with the CPCSEA registration number AVCOP/IAEC/1153/01. Wistar rats, weighing 200-250 g, were taken for the study. The animals fasted for $12 \mathrm{hrs}$ before the commencement of the experiment. Radiolabeled (>90\%) multiparticulates (50 mg) of the formulation without drug was administered orally to the animals with 
the help of feeding tube, followed by sufficient volume of drinking water. All four legs of rat were tied over a piece of plywood, and the location of the formulation in GI tract was monitored keeping the subject in front of a gamma camera. The total radiation dosimetry for each rat was $0.1 \mathrm{mSv}$. Scintigraphy image was captured using a Siemens E-Cam gamma camera fitted with a LEHR collimator. The image schedule was as follows: Immediate, 15, 30, 60, 120, 180, 240, 300, and 360 minutes. During the gamma scintigraphy scanning, the animals were freed and allowed to move and carry out normal activity $[7,8]$.

\section{Histopathology evaluation}

The study reported here adheres to the principle of laboratory animal care and was approved by the Institutional Ethical Committee AVCOP/ IAEC/1153/01.

Induction of inflammation by 2, 4, 6, trinitrobenzene sulfonic acid These studies were carried out on Wistar male rats aged 8-12 weeks and weighing 230-250 g. Animals were housed in an air-conditioned room at $22 \pm 3^{\circ} \mathrm{C}, 55 \pm 5 \%$ humidity, $12 \mathrm{hrs} \mathrm{light} / \mathrm{dark}$ cycles, and allowed free access to water and laboratory chow for the duration of the studies. To induce the model of chronic inflammation in the rat colon, the method described by Morris et al. (1989) was followed with some modification. Briefly, rats were arbitrarily separated into treatment groups, fasted for $48 \mathrm{hrs}$ with free access to water and then anesthetized with ketamine [9].

In our studies, $0.5 \mathrm{ml}$ of solution of $2,4,6$, trinitrobenzene sulfonic acid at a dosage of $81 \mathrm{mg} / \mathrm{kg}$-body weight dissolved in $50 \%$ ethanol $(\mathrm{v} / \mathrm{v})$ was inserted rectally into the colon using graduated rubber canula such that the tip was $8 \mathrm{~cm}$ proximal to the anus was instilled into the lumen of the colon through rubber probe for 12 weeks consecutively. On $12^{\text {th }}$ week, the rat was sacrificed with overdose of anesthesia. The development of inflammation was evaluated with respect to colon/ body weight ratio and histological changes.

\section{Experimental design}

A total of 12 Wistar male rats were used in this study. The rats were randomized and divided into three groups of four animals each.

- Group I: Vehicle control (normal saline)

- Group II: Disease control (2, 4, 6, trinitrobenzene sulfonic acid $81 \mathrm{mg} / \mathrm{kg}$-body weight)

- Group III: Disease Group II+ciprofloxacin multiparticulate $(250 \mathrm{mg} / \mathrm{kg} /$ day $)$.

The multiparticulate of $250 \mathrm{mg} / \mathrm{kg} /$ day of ciprofloxacin (Group III) calculated from the dose from humans (70 kg) (Sandborn and Hanaure, 2003) were also administered by oral gavage once a day for 3 days in the period when inflammation developed in colon area after $12^{\text {th }}$ week [10-12].

\section{Histopathological study}

The tissue sample was appropriately trimmed and washed under running water and processed in different grades of isopropanol, passed through xylene clearance, and molten paraffin. Paraffin blocks were prepared, 3-5 $\mu$ thick section from each block were cut and stained with the hematoxylin and eosin stain [13]. After mounting with DPX mountant, the slides were cleaned and evaluated under a light microscope.

\section{RESULT AND DISCUSSION}

Assay was performed to analyze the percentage purity of ciprofloxacin and was found to be $98.82 \%$ pure. Appropriate dilutions were prepared for drug from the standard stock solution and scanned in the spectrum mode from $400 \mathrm{~nm}$ to $200 \mathrm{~nm}$. Ciprofloxacin showed absorbance maxima at $281 \mathrm{~nm}$ (Fig. 1).

\section{Selection of analytical concentration ranges}

From the standard stock solution of ciprofloxacin, appropriate aliquots were pipetted out into $10 \mathrm{ml}$ volumetric flasks and dilutions were made with methanol to obtain working standard solutions of concentrations 3-18 $\mu \mathrm{g} / \mathrm{ml}$. Absorbance for these solutions was measured at $281 \mathrm{~nm}$ (Table 3), and a calibration curve of absorbance against concentration was plotted (Fig. 2).

\section{Evaluation for multiparticulate}

Micromeritics studies of trial batches of multiparticulate

The various batches (trial and factorial) have the average particle size in the range of 1-1.5 mm for the drug ciprofloxacin. The particle size of multiparticulate varies with composition of polymer added in the formulation. The chitosan concentration, its molecular weight, and its viscosity affect the size range of multiparticulate. The decrease in chitosan concentration decreases the size of multiparticulate. The tapped density value ranged from 0.49 to $0.55 \mathrm{~g} / \mathrm{cm}^{3}$ for all batches. The bulk density value ranged from 0.4 to $0.53 \mathrm{~g} / \mathrm{cm}^{3}$. All formulation showed good flowability as expressed in terms of angle of repose and was found within

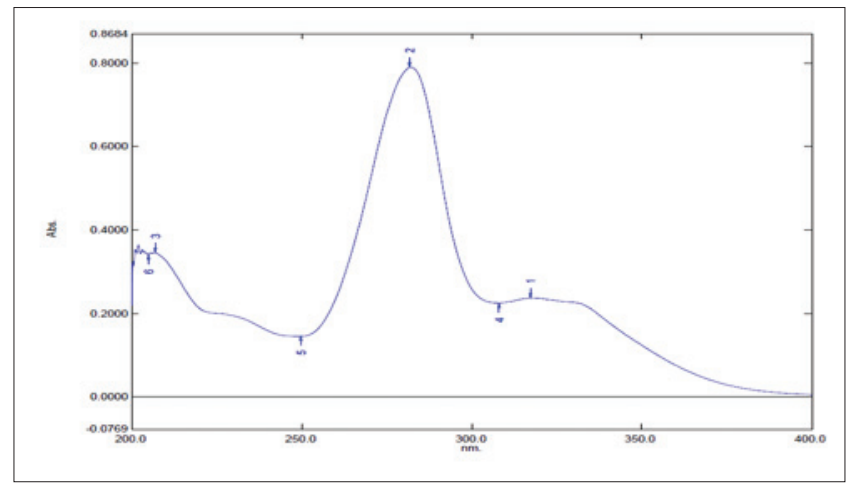

Fig. 1: Ultraviolet spectrum of ciprofloxacin

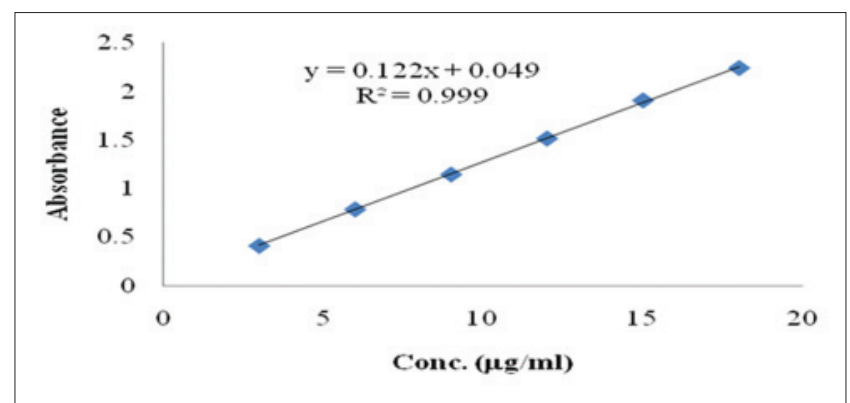

Fig. 2: Calibration curve of ciprofloxacin

Table 3: Summary of results of regression analysis for responses R1 to R6

\begin{tabular}{|c|c|c|c|c|c|c|c|c|}
\hline Responses & Models & $\mathbf{R}^{2}$ & Adjusted $\mathbf{R}^{2}$ & Predicted $\mathrm{R}^{2}$ & Adequate precision & SD & $\% \mathrm{CV}$ & PRESS \\
\hline $\mathrm{R} 1$ & Quadratic & 0.9354 & 0.8523 & -0.0322 & 8.5540 & 3.1098 & 4.3066 & 1081.75 \\
\hline $\mathrm{R} 2$ & Quadratic & 0.9294 & 0.8386 & -0.1287 & 13.0011 & 2.0794 & 2.4370 & 483.96 \\
\hline R3 & Quadratic & 0.9039 & 0.7805 & -0.5355 & 9.7748 & 2.5858 & 3.6804 & 748.67 \\
\hline R4 & Quadratic & 0.9818 & 0.9584 & 0.7117 & 22.7012 & 1.0817 & 1.3835 & 129.75 \\
\hline R5 & Quadratic & 0.9947 & 0.9879 & 0.9160 & 41.2671 & 0.3429 & 0.4049 & 13.10 \\
\hline R6 & Quadratic & 0.9574 & 0.9028 & 0.3461 & 12.0802 & 1.0841 & 1.1880 & 126.52 \\
\hline
\end{tabular}

SD: Standard deviation, CV: Coefficient of variation, PRESS: Predicted residual sum of squares 
the range of $25-35^{\circ}$, which is an appreciable limit for multiparticulate to show flow property while formulating in the dosage form (Tables 4 and 5)

\section{Swelling studies of multiparticulate of ciprofloxacin}

Swelling index was calculated with respect to time. Swelling index increased with weight gain by the multiparticulate was increased proportionally with the rate of hydration. Multiparticulate swelling is influenced by the environmental $\mathrm{pH}$, being generally greater at lower rather than higher $\mathrm{pH}$ value.

The SR of batch C5a was found to be high as compared to other formulation (Table 6). This might be due to increase in concentration of chitosan in the formulation. Initially, all the batches swell slowly but achieve maximum swelling among other concentrations (Fig. 3).
Swelling studies of multiparticulate of factorial batches

The SR of factorial batch of ciprofloxacin C1, C2, C4, and C7 was found to be high as compared to other formulation among this four batches; batch C4 shows maximum swelling, i.e. $1.81 \pm 0.05$ (Table 7). This might be due to increase in concentration of chitosan in the formulation. Initially, all the batches swell slowly but achieve maximum swelling among other concentrations (Fig. 4).

Percentage yield of multiparticulate formed of ciprofloxacin The prepared multiparticulate gives good percentage yield. The percentage yield of multiparticulate determined by weighing after drying. The maximum percentage yield was found for trial batches C3a, $\mathrm{C} 5 \mathrm{a}, \mathrm{C} 3 \mathrm{~b}$, and C5b and was found to be $92.58 \pm 1.14 \%, 95.32 \pm 0.45 \%$, $92.55 \pm 2.12 \%$, and $94.30 \pm 2.13 \%$, respectively (Table 8 and Fig. 5).

Table 4: Analysis of variance for response R1 (entrapment efficiency)

\begin{tabular}{|c|c|c|c|c|c|c|}
\hline Source & Sum of squares & Df & Mean square & F value & $p$ value $P>F$ & Significance \\
\hline Model & 980.2986 & 9 & 108.9220 & 11.2627 & 0.002132 & Significant \\
\hline $\mathrm{A}-\mathrm{CH}$ & 0.03645 & 1 & 0.0364 & 0.003768996 & 0.9527 & \\
\hline $\mathrm{B}-\mathrm{GG}$ & 43.0128 & 1 & 43.0128 & 4.447602611 & 0.0729 & \\
\hline C-CC & 0.0946 & 1 & 0.0946 & 0.009783104 & 0.9239 & \\
\hline $\mathrm{AB}$ & 37.3321 & 1 & 37.3321 & 3.860206663 & 0.0901 & \\
\hline $\mathrm{AC}$ & 0.1024 & 1 & 0.1024 & 0.010588345 & 0.9209 & \\
\hline $\mathrm{BC}$ & 0.1332 & 1 & 0.1332 & 0.013775706 & 0.9098 & \\
\hline $\mathrm{B}^{2}$ & 796.1973 & 1 & 796.1973 & 82.32824867 & $4.05 \mathrm{E}-05$ & \\
\hline $\mathrm{C}^{2}$ & 68.7650 & 1 & 68.7650 & 7.110431499 & 0.0321 & \\
\hline Residual & 67.6970 & 7 & 9.6710 & & & \\
\hline Lack of fit & 67.6002 & 3 & 22.5334 & 931.1332645 & $3.83 \mathrm{E}-06$ & Significant \\
\hline Pure error & 0.0968 & 4 & 0.0242 & 11.26273892 & 0.0021 & \\
\hline Correlation total & 1047.995694 & 16 & & & & \\
\hline
\end{tabular}

Table 5: Analysis of variance for response R2 (mucoadhesion)

\begin{tabular}{|c|c|c|c|c|c|c|}
\hline Source & Sum of squares & df & Mean square & F value & $p$ value $P>F$ & Significance \\
\hline Model & 398.4785 & 9 & 44.27539 & 10.23925 & 0.00286 & Significant \\
\hline $\mathrm{A}-\mathrm{CH}$ & 242 & 1 & 242 & 55.96558 & 0.00014 & \\
\hline$B-G G$ & 47.97101 & 1 & 47.97101 & 11.09391 & 0.012578 & \\
\hline $\mathrm{C}-\mathrm{CC}$ & 3.419113 & 1 & 3.419113 & 0.790713 & 0.403406 & \\
\hline $\mathrm{AB}$ & 43.0336 & 1 & 43.0336 & 9.952067 & 0.016047 & \\
\hline $\mathrm{AC}$ & 3.3856 & 1 & 3.3856 & 0.782963 & 0.405603 & \\
\hline $\mathrm{BC}$ & 0.416025 & 1 & 0.416025 & 0.096211 & 0.765456 & \\
\hline $\mathrm{B}^{2}$ & 31.9638 & 1 & 31.9638 & 7.392035 & 0.029816 & \\
\hline $\mathrm{C}^{2}$ & 4.083084 & 1 & 4.083084 & 0.944265 & 0.363556 & \\
\hline Residual & 30.26861 & 7 & 4.324086 & & & \\
\hline Lack of fit & 30.24573 & 3 & 10.08191 & 1762.571 & $1.07 \mathrm{E}-06$ & Significant \\
\hline Pure error & 0.02288 & 4 & 0.00572 & & & \\
\hline Correlation total & 428.7472 & 16 & & & & \\
\hline
\end{tabular}

Table 6: Analysis of variance for response R3 (drug release at $9 \mathrm{hr}$ )

\begin{tabular}{|c|c|c|c|c|c|c|}
\hline Source & Sum of squares & df & Mean square & F value & $p$ value $P>F$ & Significance \\
\hline Model & 440.7568 & 9 & 48.97298 & 7.323789 & 0.007795 & Significant \\
\hline $\mathrm{A}-\mathrm{CH}$ & 254.5896 & 1 & 254.5896 & 38.07325 & 0.000458 & \\
\hline B-GG & 34.48651 & 1 & 34.48651 & 5.157373 & 0.057394 & \\
\hline $\mathrm{C}-\mathrm{CC}$ & 11.95605 & 1 & 11.95605 & 1.787998 & 0.222986 & \\
\hline $\mathrm{AB}$ & 0.403225 & 1 & 0.403225 & 0.060301 & 0.813065 & \\
\hline $\mathrm{AC}$ & 20.7936 & 1 & 20.7936 & 3.109632 & 0.121196 & \\
\hline $\mathrm{BC}$ & 7.6729 & 1 & 7.6729 & 1.147463 & 0.319618 & \\
\hline $\mathrm{B}^{2}$ & 14.57065 & 1 & 14.57065 & 2.179005 & 0.183416 & \\
\hline $\mathrm{C}^{2}$ & 22.8144 & 1 & 22.8144 & 3.411838 & 0.10722 & \\
\hline Residual & 46.80786 & 7 & 6.686836 & & & \\
\hline Lack of fit & 46.79038 & 3 & 15.59679 & 3569.06 & $2.61 \mathrm{E}-07$ & Significant \\
\hline Pure error & 0.01748 & 4 & 0.00437 & & & \\
\hline Correlation total & 487.5647 & 16 & & & & \\
\hline
\end{tabular}




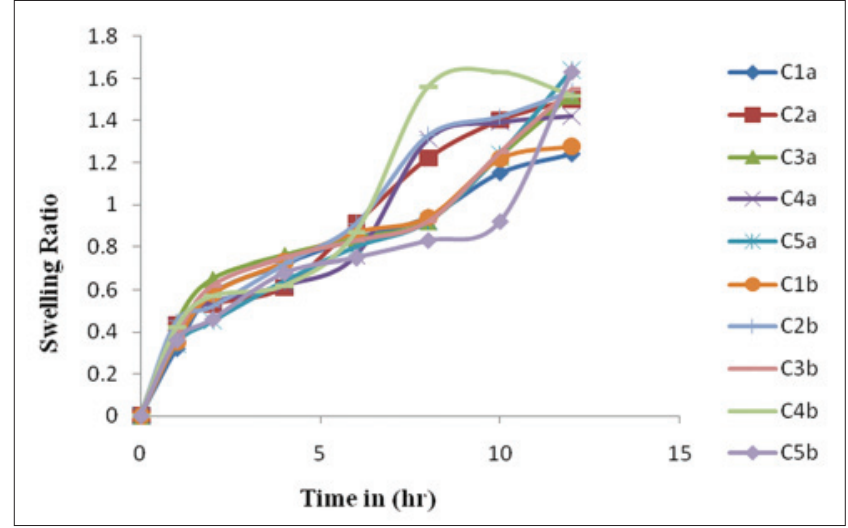

Fig. 3: Swelling studies of multiparticulate of trial batch of ciprofloxacin

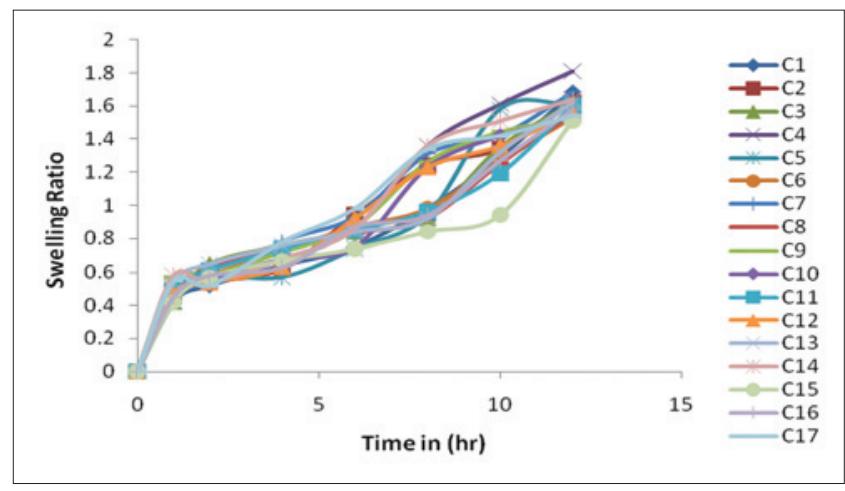

Fig. 4: Swelling studies of multiparticulate of factorial batch of ciprofloxacin
Prepared factorial batches were also showed good percentage yield for batch C1, C2, C4, and C7 (91.20 $\pm 1.22 \%, 93.83 \pm 2.14 \%, 95.12 \pm 2.15 \%$, and $94.16 \pm 1.15 \%$, respectively) show good result as compared with other batches (Table 9 and Fig. 6).

\section{Drug entrapment of multiparticulate of ciprofloxacin}

The prepared multiparticulate was evaluated for drug entrapment study. The \% drug entrapment in all formulation was found to be good, i.e., above $60 \%$ (Table 10). The multiparticulate of trial batches ciprofloxacin C3a, C5a, C3b, and C5b $(72.37 \pm 1.13 \%, 84.68 \pm 1.15 \%$, $79.31 \pm 1.15 \%$, and $83.06 \pm 1.8 \%$, respectively) formulation showed a higher entrapment efficiency, whereas the other formulations showed lesser entrapment than this formulation. This can be attributed to the polymer composition of chitosan:guar gum in 2:1 ratio (Fig. 7).

Prepared factorial batches of multiparticulate also show good \% drug entrapment in the range of $60-80 \%$. For batch C4 shows good $\%$ entrapment, i.e., $80.24 \pm 4.12 \%$ then the other formulation. From this data, it is clear that increase in polymer concentration, especially chitosan increases the entrapment of drug (Fig. 8).

\section{Ex vivo mucoadhesion study of batches}

The mucoadhesive properties of the multiparticulate were evaluated by ex vivo mucoadhesion study. After the intervals of $12 \mathrm{hrs}$, the weight of microspheres leached out was measured.

Form the trial batches, $\mathrm{C} 5 \mathrm{a}$ and $\mathrm{C} 5 \mathrm{~b}(84.68 \pm 1.15$ and $80.48 \pm 0.37$ respectively) batches show better adhesion as compared to the others. From this result, we can conclude that increase in polymer concentration (especially chitosan) increases the adhesion of multiparticulate because of increase in molecular weight of chitosan and increased viscosity then guar gum. This data also reveal that there is no influence of coat composition on adhesion because both the batches shows similar result whether it is for $10 \%$ (low) coat or $15 \%$ coat composition (high) (Fig. 9).

Table 7: Analysis of variance for response R4 (drug release at $12 \mathrm{hr}$ )

\begin{tabular}{|c|c|c|c|c|c|c|}
\hline Source & Sum of squares & df & Mean square & F value & $p$ value $P>F$ & Significance \\
\hline Model & 441.9632 & 9 & 49.10702 & 41.96248 & $2.88 \mathrm{E}-05$ & Significant \\
\hline $\mathrm{A}-\mathrm{CH}$ & 132.0313 & 1 & 132.0313 & 112.8222 & $1.44 \mathrm{E}-05$ & \\
\hline$B-G G$ & 58.86125 & 1 & 58.86125 & 50.29758 & 0.000195 & \\
\hline $\mathrm{C}-\mathrm{CC}$ & 12.005 & 1 & 12.005 & 10.2584 & 0.015006 & \\
\hline $\mathrm{AB}$ & 0.0361 & 1 & 0.0361 & 0.030848 & 0.865553 & \\
\hline $\mathrm{AC}$ & 0.3364 & 1 & 0.3364 & 0.287457 & 0.608462 & \\
\hline $\mathrm{BC}$ & 28.6225 & 1 & 28.6225 & 24.45824 & 0.001665 & \\
\hline$A^{2}$ & 106.4031 & 1 & 106.4031 & 90.92259 & 2.93E-05 & \\
\hline $\mathrm{B}^{2}$ & 90.96381 & 1 & 90.96381 & 77.72957 & $4.88 \mathrm{E}-05$ & \\
\hline $\mathrm{C}^{2}$ & 22.8193 & 1 & 22.8193 & 19.49934 & 0.003097 & \\
\hline Residual & 8.19182 & 7 & 1.17026 & & & \\
\hline Lack of fit & 8.1009 & 3 & 2.7003 & 118.7989 & 0.00023 & Significant \\
\hline Pure error & 0.09092 & 4 & 0.02273 & & & \\
\hline Correlation total & 450.155 & 16 & & & & \\
\hline
\end{tabular}

Table 8: Analysis of variance for response R5 (drug release at $18 \mathrm{hr}$ )

\begin{tabular}{|c|c|c|c|c|c|c|}
\hline Source & Sum of squares & df & Mean square & F value & $p$ value $P>F$ & Significance \\
\hline Model & 155.25 & 9 & 17.25 & 146.6525 & $3.92 \mathrm{E}-07$ & Significant \\
\hline $\mathrm{A}-\mathrm{CH}$ & 126.2461 & 1 & 126.2461 & 1073.293 & 6.39E-09 & \\
\hline $\mathrm{B}-\mathrm{GG}$ & 6.283513 & 1 & 6.283513 & 53.41987 & 0.000162 & \\
\hline $\mathrm{C}-\mathrm{CC}$ & 0.032512 & 1 & 0.032512 & 0.276408 & 0.615303 & \\
\hline $\mathrm{AB}$ & 0.0169 & 1 & 0.0169 & 0.143677 & 0.715888 & \\
\hline $\mathrm{AC}$ & 0.2601 & 1 & 0.2601 & 2.211265 & 0.180601 & \\
\hline $\mathrm{BC}$ & 0.001225 & 1 & 0.001225 & 0.010414 & 0.921578 & \\
\hline $\mathrm{B}^{2}$ & 2.771059 & 1 & 2.771059 & 23.55842 & 0.001848 & \\
\hline $\mathrm{C}^{2}$ & 3.870322 & 1 & 3.870322 & 32.90391 & 0.000708 & \\
\hline Residual & 0.823375 & 7 & 0.117625 & & & \\
\hline Lack of fit & 0.818575 & 3 & 0.272858 & 227.3819 & $6.36 \mathrm{E}-05$ & Significant \\
\hline Pure error & 0.0048 & 4 & 0.0012 & & & \\
\hline Correlation total & 156.0734 & 16 & & & & \\
\hline
\end{tabular}


Table 9: Analysis of variance for response R6 (drug release at $24 \mathrm{hr}$ )

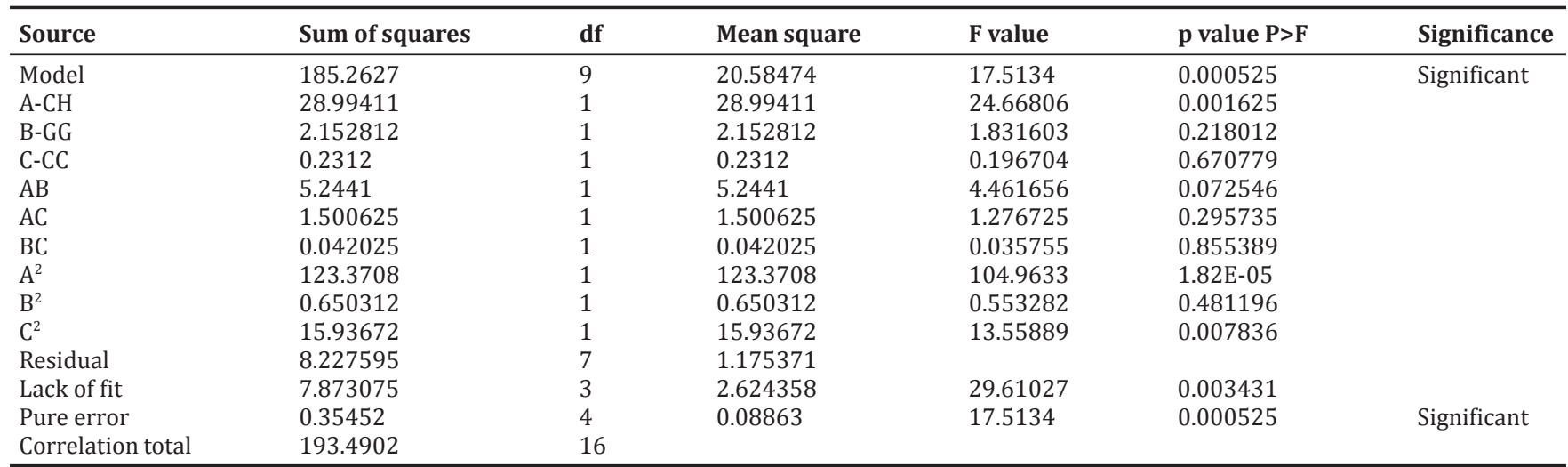

Table 10: Changes in body weight of Wistar male rat male rat during study

\begin{tabular}{lllll}
\hline S. No. & Groups & $\begin{array}{l}\text { Initial body } \\
\text { weight }(g)\end{array}$ & $\begin{array}{l}\text { Final body } \\
\text { weight }(g)\end{array}$ & $\begin{array}{l}\text { Weight } \\
\text { gain (g) }\end{array}$ \\
\hline 1 & Group I & $236.13 \pm 2.14$ & $237.06 \pm 2.03$ & $242.11 \pm 1.10$ \\
2 & Group II & $235.21 \pm 3.23$ & $229.34 \pm 1.13$ & $237.45 \pm 1.03$ \\
3 & Group III & $243.02 \pm 1.23$ & $249.22 \pm 2.43$ & $250.00 \pm 2.03$ \\
\hline \multicolumn{4}{l}{ Each sample was analyzed in triplicate $(\mathrm{n}=3)$}
\end{tabular}

\section{$\%$ Yield}

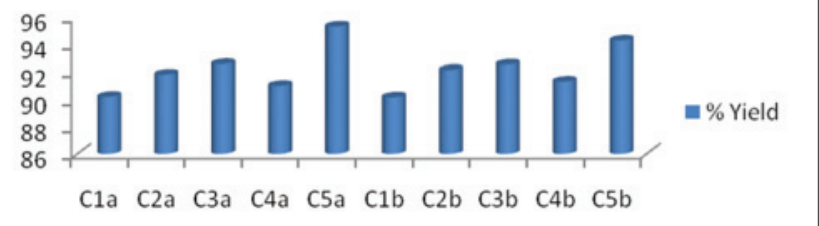

Fig. 5: Percentage yield of multiparticulate of trial batch of ciprofloxacin

\section{$\%$ Yield}

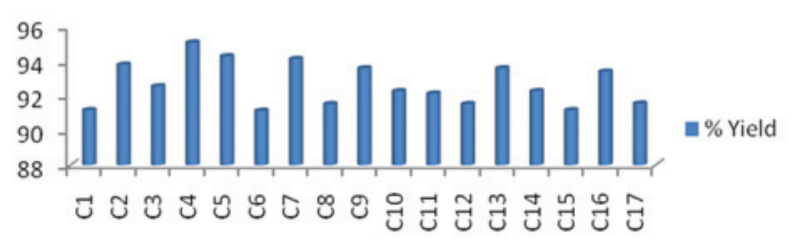

Fig. 6: Percentage yield of multiparticulate of factorial batch of ciprofloxacin

\section{\% Drug entrapment}

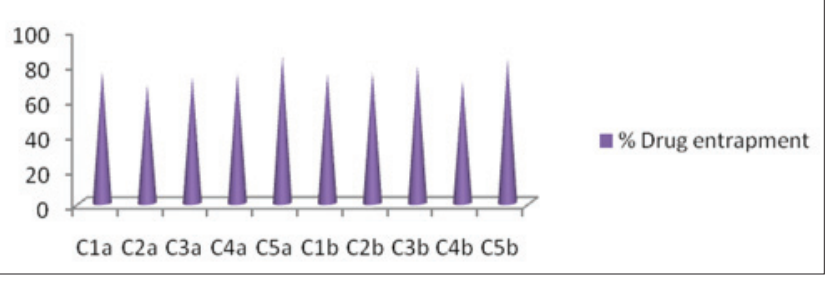

Fig. 7: \% drug entrapped of trial batches of ciprofloxacin

Factorial batches also show good adhesion, i.e. more than $68 \%$. For ciprofloxacin factorial batches, batch C4 $(90.23 \pm 2.02 \%)$ shows better adhesion than the others. This data for factorial batches conclude that increase in polymer concentration increases the adhesion, and it is not affected by coat composition (Fig. 10).

\section{In vitro drug release studies for batches of ciprofloxacin}

In vitro dissolution study was conducted to understand in vitro drug release profile of coated multiparticulate. The purpose of this formulation was to avoid release of drug in gastric and upper intestinal region but to release the drug slowly in the lower part of the intestine maximizing drug concentration in the colon. Enteric-coated multiparticulate, coated with a coat composition of Eudragit S and L $100(10 \%$, and 15\%), showed no drug release in simulated gastric fluid up to 2 hrs indicating the intactness of the applied coat. Dissolution studies were continued for a further $4 \mathrm{hr}$ period in simulated intestinal media showing relatively low drug release, i.e., up to 20-25\%. Release of drug beyond $6 \mathrm{hrs}$ in simulated colon fluid was varied substantial with over $95 \%$ release in $24 \mathrm{hrs}$ for trial batches of ciprofloxacin; batch C5a $(92.87 \pm 0.41)$ and C5b $(90.42 \pm 0.43)$ shows better release as compared to others (Fig. 11).

For factorial batches, absorbance of sample of dissolution study was done after 6 hrs by consider the data from trial batches, i.e. negligible release (30\%) of drug up to $6 \mathrm{hr}$. Analysis was done on samples of 9 , 12,18 , and $24 \mathrm{hrs}$. The results show that for ciprofloxacin batch C4 shows maximum release of drug, i.e., $97.64 \pm 0.15 \%$, compared to other formulations (Fig. 12).

It was interesting to observe low release profiles of coated multiparticulate in GIT. This could be due to the cross-linking of chitosan which did not disintegrate under the influence of colon enzymes and thus can be stated that the multiparticulate retained their integrity. The release could be by diffusion and/or by erosion of the multiparticulate matrix.

\section{Release kinetics}

The release rate constant was calculated from the slope of appropriate equations, and the correlation coefficient (R) was determined for all the formulations. The release profile and the entrapment efficiency of formulation of factorial batches $\mathrm{C} 4$ for, was found to be satisfactory in comparison to other formulation, the discussion on the kinetics of other formulations was not considered further.

In vitro drug release of C4 was best explained by Korsmeyer-Peppas equation with highest linearity $R^{2}=0.9979$ followed by Higuchi's equation, $\mathrm{R}^{2}=0.9944$ and first order $\mathrm{R}^{2}=0.9811$. This indicates that the drug was diffused from the polymeric matrix. The drug release was found to be closed to Higuchi kinetics which indicates that the drug diffuses at a comparatively slower rate as the distance of diffusion increases. Further, the value of " $n$ " from Korsmeyer-Peppas equation for C4 $(n=0.8054)$ indicates a purely relaxed controlled delivery which referred to as Case II transport. Occasionally, values of $n>0.89$ have been observed, which have been regarded as Super Case II kinetics. Our 


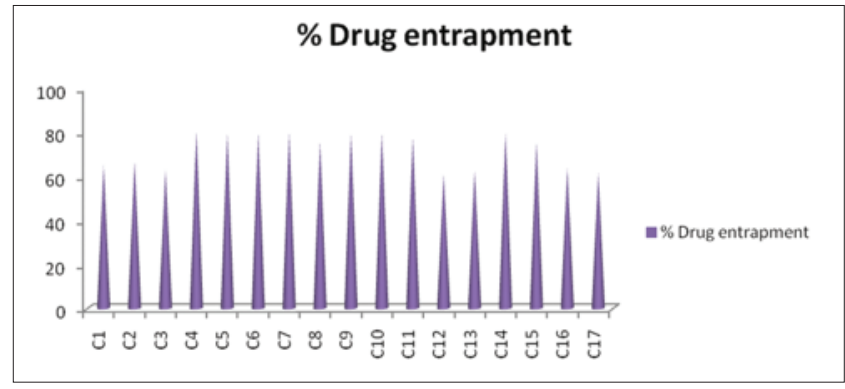

Fig. 8: \% drug entrapped of factorial batches of ciprofloxacin

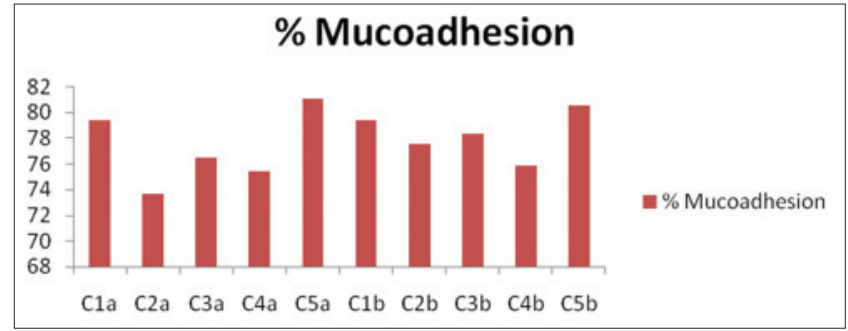

Fig. 9: Ex vivo mucoadhesion study of trial batches of ciprofloxacin

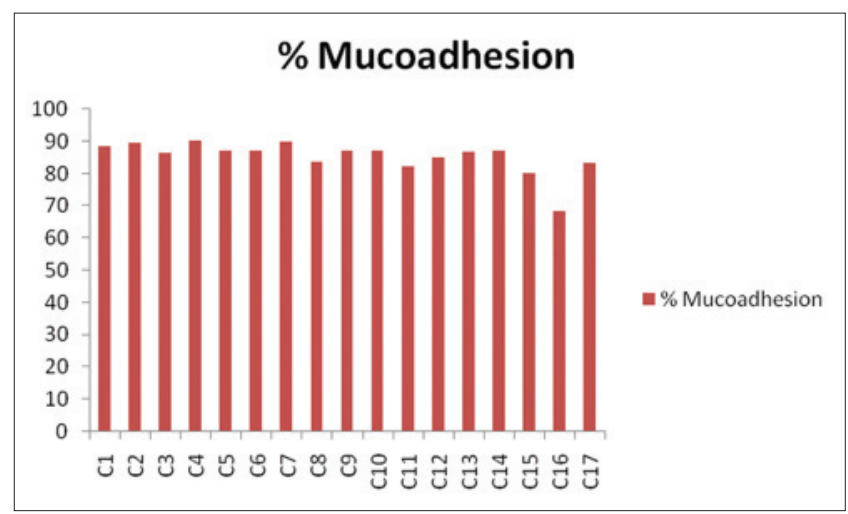

Fig. 10: Ex vivo mucoadhesion study of factorial batches of ciprofloxacin

results clearly advocate the non-Fickian diffusion owing to the coupling of diffusion process with the mechanical response of the polymer chitosan and guar gum.

\section{Factorial design data analysis}

\section{Experimental design analysis}

Use of experimental design allows systematic optimization procedures which carried out by selecting an objective function, finding the most important or contributing factors, and investigating the relationship between responses and factors by the so-called RSM. Objective function for the present study was selected as maximizing the polymer concentration and polymer coating, i.e. coat composition efficiency while studying its effect on entrapment efficiency, mucoadhesion, and drug release at $9,12,18$, and 24 hrs for ciprofloxacin.

Box-Behnken design was used to statistically optimize the processing parameters and evaluate the main effects, interaction effects, and quadratic effects of the processing parameters on the polymer concentration and enteric coating on formulations. A 3-factor, 3-level design was used to explore the quadratic response surfaces and for constructing second order polynomial models using design expert (Version 9.0.5.1, Stat-Ease Inc., Minneapolis, MN). The Box-Behnken design was specifically selected since it requires fewer runs than a central composite design, in cases of three or four variables. This cubic

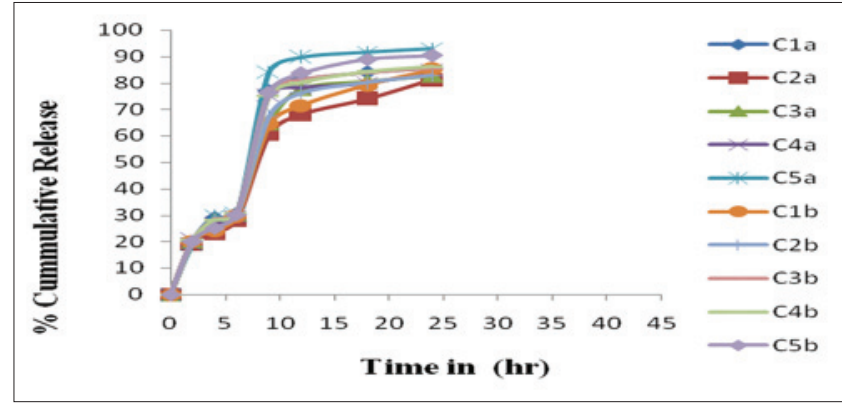

Fig. 11: \% cumulative release of batches of ciprofloxacin

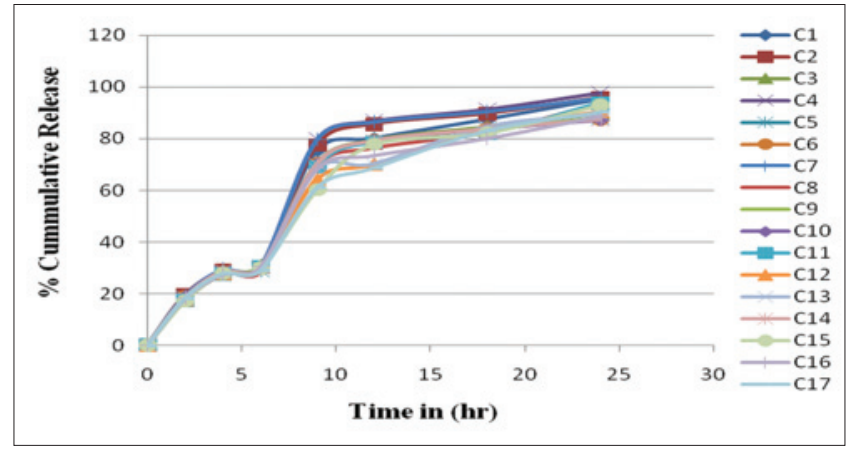

Fig. 12: \% cumulative release of factorial batches of ciprofloxacin

design is characterized by set of points lying at the midpoint of each edge of a multidimensional cube and center point replicates $(n=1)$. A design matrix was constructed with 17 experimental runs, for which the linear computer-generated quadratic model for responses such as entrapment efficiency (R1), mucoadhesion (R2); drug release at 9 (R3), 12 (R4), 18 (R5), and 24 (R6) was giving as:

$\mathrm{R} 1=79.49-0.0675^{*} \mathrm{~A} \quad 2.31875^{*} \mathrm{~B} \quad-0.10875^{*} \mathrm{C}-3.055^{*} \mathrm{AB} \quad-0.16^{*} \mathrm{AC}$ 0.1825*BC $2.32125 * \mathrm{~A}^{2}-13.75125 * \mathrm{~B}^{2}-4.04125^{*} \mathrm{C}^{2}$

$\mathrm{R} 2=87.218+5.5^{*} \mathrm{~A} \quad 2.44875 * \mathrm{~B} \quad 0.65375^{*} \mathrm{C} \quad-3.28 * \mathrm{AB} \quad-0.92 * \mathrm{AC}$ $-0.3225 * \mathrm{BC}-2.24775 * \mathrm{~A}^{2}-2.75525 * \mathrm{~B}^{2} 0.98475 * \mathrm{C}^{2}$

$\mathrm{R} 3=70.188+5.64125 * \mathrm{~A} \quad 2.07625^{*} \mathrm{~B} \quad 1.2225^{*} \mathrm{C} \quad 0.3175^{*} \mathrm{AB} \quad-2.28^{*} \mathrm{AC}$ $-1.385 * \mathrm{BC} 4.33975 * \mathrm{~A}^{2}-1.86025 * \mathrm{~B}^{2}-2.32775^{*} \mathrm{C}^{2}$

$\mathrm{R} 4=79.106+4.0625 * \mathrm{~A} 2.7125 * \mathrm{~B}-1.225 * \mathrm{C} 0.095 * \mathrm{AB} 0.29 * \mathrm{AC}-2.675 * \mathrm{BC}$ $5.027^{*} \mathrm{~A}^{2}-4.648^{*} \mathrm{~B}^{2}-2.328^{*} \mathrm{C}^{2}$

$\mathrm{R} 5=83.72+3.9725^{*} \mathrm{~A} \quad 0.88625^{*} \mathrm{~B} \quad-0.06375^{*} \mathrm{C} \quad 0.065^{*} \mathrm{AB} \quad-0.255^{*} \mathrm{AC}$ $-0.0175 * \mathrm{BC} 1.94125^{*} \mathrm{~A}^{2}-0.81125^{*} \mathrm{~B}^{2} 0.95875^{*} \mathrm{C}^{2}$

$\mathrm{R} 6=87.604+1.90375 * \mathrm{~A} \quad 0.51875 * \mathrm{~B} \quad-0.17 * \mathrm{C} \quad-1.145 * \mathrm{AB} \quad-0.6125 * \mathrm{AC}$ $-0.1025 * \mathrm{BC} 5.413 * \mathrm{~A}^{2} 0.393 * \mathrm{~B}^{2} 1.9455^{*} \mathrm{C}^{2}$

For ciprofloxacin response R1, 79.49 is an intercept, and 2.31875, $-0.10875,-3.055,-0.16,0.1825,2.32125,-13.75125$, and -4.04125 are regression coefficient computed from the observed experimental values of R1 from experimental runs; $A, B$, and $C$ are the coded levels of independent variables. The terms $\mathrm{AB}, \mathrm{AC}, \mathrm{BC}$, and $\mathrm{A}^{2}, \mathrm{~B}^{2}, \mathrm{C}^{2}$ represent the interaction and quadratic terms, respectively. Same is for the responses $\mathrm{R} 2, \mathrm{R} 3, \mathrm{R} 4, \mathrm{R} 5$, and R6.

Independent variable studied was polymer concentration, i.e., chitosan (A), guar gum (B), and coat composition of Eudragit L and S 100 (C). The dependent variables were the entrapment efficiency (R1), mucoadhesion (R2); drug release at 9 (R3), 12 (R4), 18 (R5), and 24 (R6). The range of independent variables under study along with their low, medium, and high levels, which were selected based on the 
results from preliminary experimentation. The polymer concentration, i.e., chitosan (A), guar gum (B), and coat composition of Eudragit $\mathrm{L}$ and S 100 (C) used to prepare the 17 experimental formulations. The polynomial equations can be used to draw a conclusion after considering the magnitude coefficient and the mathematical sign that the coefficient carries. A high positive or negative value in the equation represents that by making a minor change in the setting of that factor one may obtain a significant change in the dependent variable.

Statistical validity of the polynomials was established on the basis of ANOVA provision in the Design Expert Software. The level of significance was considered at $>\mathrm{F}<0.05$. The best-fitting mathematical model was selected based on the comparison of several statistical parameters, including the $\mathrm{CV}$, the multiple correlation coefficient $\left(\mathrm{R}^{2}\right)$, the adjusted multiple correlation coefficient (adjusted $\mathrm{R}^{2}$ ), and the PRESS, provided by the software. PRESS indicates how well the model fits the data, and for the chosen model, it should be small relative to the other models under consideration. The 3D response surface graphs and the 2D contour plots were also generated by the Design Expert ${ }^{\circledR}$ Software. These plots are very useful to see interaction effects of the factors on responses.

\section{Full and reduced model assessment for the dependent variables} The result of responses R1 to R6 was 95\% for ciprofloxacin. All the responses observed for seventeen processing variables were fitted to various models using "Design Expert Software." It was observed that the best-fitted models were quadratic. The values of $\mathrm{R}^{2}$, adjusted $\mathrm{R}^{2}$, predicted $\mathrm{R}^{2}, \mathrm{SD}$, and $\% \mathrm{CV}$ along with the regression equation are generated for each response. It was observed that the independent variable viz. A (chitosan) had a positive effect on drug release (R). Other independent variables, viz., B (guar gum) and C (coat composition) had a negligible effect (R) (Table 3).

Response R1 (entrapment efficiency) A negative "Pred R" implies that the overall mean was a better predictor of your response than the current model. "Adeq Precision" measures the signal to noise ratio. A ratio $>4$ was desirable. Your ratio of 8.554 indicates an adequate signal. This model can be used to navigate the design space. Response R2

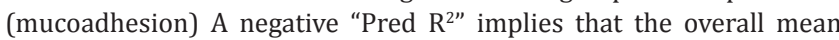
was a better predictor of your response than the current model. "Adeq Precision" measures the signal to noise ratio. A ratio $>4$ was desirable. Your ratio of 13.001 indicates an adequate signal. This model can be used to navigate the design space. Response R3 (drug release at $9 \mathrm{hr}$ ) A

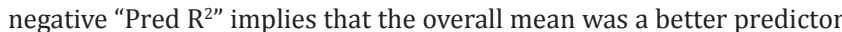
of your response than the current model. "Adeq Precision" measures the signal to noise ratio. A ratio $>4$ was desirable. Your ratio of 9.775 indicates an adequate signal. This model can be used to navigate the design space.

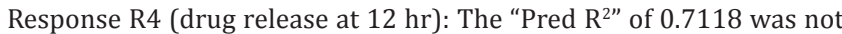

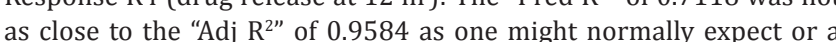
possible problem with your model and/or data. Things to consider are model reduction, response transformation, outliers, etc. All empirical models should be tested by doing confirmation runs. "Adeq Precision" measures the signal to noise ratio. A ratio $>4$ is desirable. Your ratio of 22.701 indicates an adequate signal. This model can be used to navigate the design space. Response R5 (drug release at $18 \mathrm{hr}$ ): The

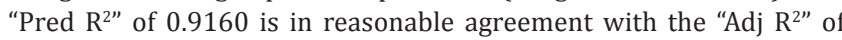
0.9879 , i.e. the difference is $<0.2$. "Adeq Precision" measures the signal to noise ratio. A ratio $>4$ is desirable. Your ratio of 41.267 indicates an adequate signal. This model can be used to navigate the design space.

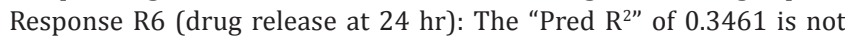

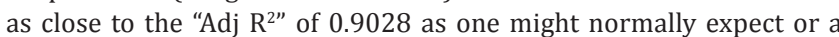
possible problem with your model and/or data. Things to consider are model reduction, response transformation, outliers, etc. All empirical models should be tested by doing confirmation runs. "Adeq Precision" measures the signal to noise ratio. A ratio $>4$ is desirable. Your ratio of 12.080 indicates an adequate signal. This model can be used to navigate the design space.
Statistical validation of the polynomial equations generated by design expert and estimation of the significance of the models was established on the basis of ANOVA provision of the software (Table 4).

For response R1 (entrapment efficiency), the model F value of 11.2627 implies the model is significant. There is only a $0.21 \%$ chance that a "Model F value" this large could occur due to noise. Values of " $p>F^{\prime}$ $<0.0500$ indicate model terms are significant. In this case, B (guar gum), $++2+-$, and $\mathrm{C}++2+-$ are significant model terms. Values $>0.1000$ indicate the model terms are not significant. The "Lack of Fit $\mathrm{F}$ value" of 931.13 implies the lack of fit is significant. There is only a $0.01 \%$ chance that a "Lack of fit F value" this large could occur due to noise. The $\mathrm{p}$ values for response R1 (entrapment efficiency) represent that the linear contribution (A, B, and C) is a significant model. The values obtained for main effects of the independent variables from equation indicate that chitosan (A), guar gum (B), and coat composition have a positive effect on the response R1 (entrapment efficiency). From the figure 13 and 14 of the response curve of entrapment efficiency for multiparticulate, it is observed that as the guar gum (B) concentration at high level (1) increases entrapment efficiency of multiparticulate significantly. From the equation, they indicate that concentrations of chitosan (A) at medium level (0) were effective for response R1 (entrapment efficiency). On the other hand, the coat composition at a low level $(-1)$ is sufficient to reach the multiparticulate to the colon (Figs. 13 and 14).

For response R2 (mucoadhesion), the model $\mathrm{F}$ value of 10.24 implies the model is significant. There is only a $0.29 \%$ chance that a "Model $F$ value" this large could occur due to noise. Values of " $p>F$ " $<0.0500$ indicate model terms are significant. In this case, A, B, AB, and B++2+are significant model terms. Values $>0.1000$ indicate the model terms are not significant. If there are many insignificant model terms (not counting those required to support hierarchy), model reduction may improve your model. The "Lack of Fit F value" of 1762.57 implies the Lack of Fit is significant. There is only a $0.01 \%$ chance that a "Lack of Fit $F$ value" this large could occur due to noise. In Table 19, $p$ values for response R2 (mucoadhesion) represent that the linear contribution (A, B, and C) is the significant model term. The values obtained for main effects of the independent variables from equation indicate that chitosan (A) and guar gum (B) have a positive effect on the response R2 (mucoadhesion). From the Figs. 46 and 47 of the response curve of mucoadhesion for multiparticulate, it is observed that as the chitosan (A) concentration at high level (1) increases entrapment efficiency of multiparticulate increases significantly. From equation, they indicate that concentrations of guar gum (B) at medium level (0) are effective for response R2 (mucoadhesion). On the other hand, the coat composition at a low level $(-1)$ is sufficient to reach the multiparticulate to colon (Figs. 15 and 16)

For response R3 (drug release at $9 \mathrm{hr}$ ), the model $\mathrm{F}$ value of 7.32 implies the model is significant. There is only a $0.78 \%$ chance that a "Model F value" this large could occur due to noise. Values of " $p>F$ " $<0.0500$ indicate model terms are significant. In this case, $\mathrm{A}$ and $\mathrm{A}++2+-$ are significant model terms. Values $>0.1000$ indicate the model terms are not significant. If there are many insignificant model terms (not counting those required to support hierarchy), model reduction may improve your model. The "Lack of Fit $\mathrm{F}$ value" of 3569.06 implies the lack of fit is significant. There is only a $0.01 \%$ chance that a "Lack of Fit F value" this large could occur due to noise. In Table 20, p values for response R3 (drug release at $9 \mathrm{hr}$ ) represent that the contribution $(\mathrm{A}, \mathrm{B}$, and $\mathrm{C})$ is significant to model term. The values obtained for main effects of the independent variables from equation indicate that chitosan (A) at high level (1) have positive effect on the response R3 (drug release at $9 \mathrm{hr}$ ). From the Figs. 48 and 49 of the response curve of drug release at $9 \mathrm{hr}$ for multiparticulate, it is observed that high (1) concentration of chitosan (A) releases the drug at $9 \mathrm{hr}$ significantly. From equation, they indicate that concentrations of guar gum (B) at medium level (0) are effective for response R3 (drug release at $9 \mathrm{hr}$ ). On the other 
hand, the coat composition at a low level $(-1)$ is sufficient to reach the multiparticulate to colon (Figs. 17 and 18).

For Response R4 (drug release at $12 \mathrm{hr}$ ), the model $\mathrm{F}$ value of 41.96 implies the model is significant. There is only a $0.01 \%$ chance that a "Model F value" this large could occur due to noise. Values of " $p>F^{\prime}$ $<0.0500$ indicate model terms are significant. In this case, A, B, C, BC $\mathrm{A}++2+-, \mathrm{B}++2+-$, and $\mathrm{C}++2+-$ are significant model terms. Values $>0.1000$ indicate the model terms are not significant. If there are many insignificant model terms (not counting those required to support hierarchy), model reduction may improve your model. The "Lack of Fit F value" of 118.80 implies the lack of fit is significant. There is only a $0.02 \%$ chance that a "Lack of Fit F value" this large could occur due to noise. The $\mathrm{p}$ values for response $\mathrm{R} 4$ (drug release at $12 \mathrm{hr}$ ) represent that the contribution of $(\mathrm{A}, \mathrm{B}$, and $\mathrm{C})$ is significant to model term. The values obtained for main effects of the independent variables from equation indicate that chitosan (A) at high level (1) have a positive effect on the response R4 (drug release at $12 \mathrm{hr}$ ). From the figure 17 and 18 of the response curve of drug release at $9 \mathrm{hr}$ for multiparticulate, it is observed that high (1) concentration of chitosan (A) releases the drug at $12 \mathrm{hr}$ significantly. From equation, they indicate that concentrations of guar gum (B) at medium level (0) are effective for response R4 (drug release at $12 \mathrm{hr}$ ). On the other hand, the coat composition at a low level $(-1)$ is sufficient to reach the multiparticulate to colon (Figs. 19 and 20)

For Response R4 (drug release at $18 \mathrm{hr}$ ), the model F value of 146.65 implies the model is significant. There is only a $0.01 \%$ chance that a "Model F Value" this large could occur due to noise. Values of " $\mathrm{p}>\mathrm{F}$ " $<0.0500$ indicate model terms are significant. In this case, A, $\mathrm{B}, \mathrm{A}++2+-, \mathrm{B}++2+-$, and $\mathrm{C}++2+-$ are significant model terms. Values $>0.1000$ indicate the model terms are not significant. If there are many insignificant model terms (not counting those required to support hierarchy), model reduction may improve your model. The "Lack of Fit F value" of 227.38 implies the lack of fit is significant. There is only a $0.01 \%$ chance that a "Lack of Fit F value" this large could occur due to noise. TheC $\mathrm{p}$ values for response $\mathrm{R} 5$ (drug release at $18 \mathrm{hr}$ ) represent

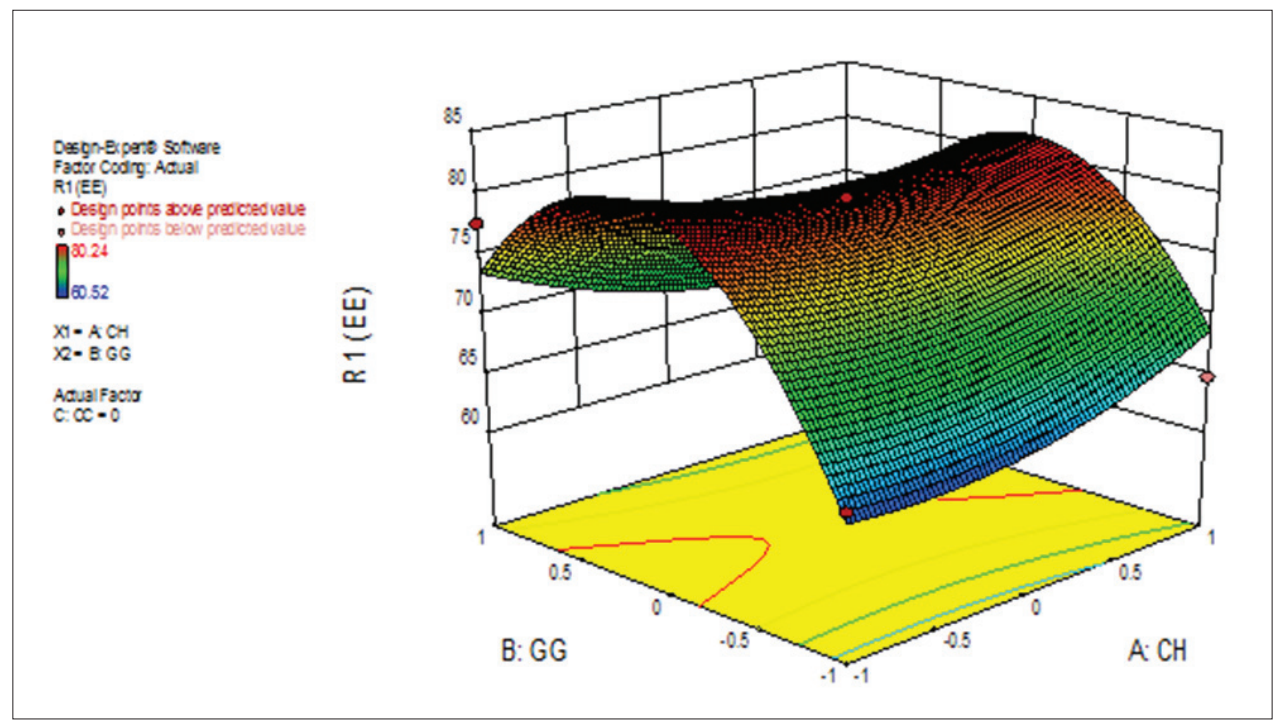

Fig. 13: 3D response curve for $\mathrm{R} 1$

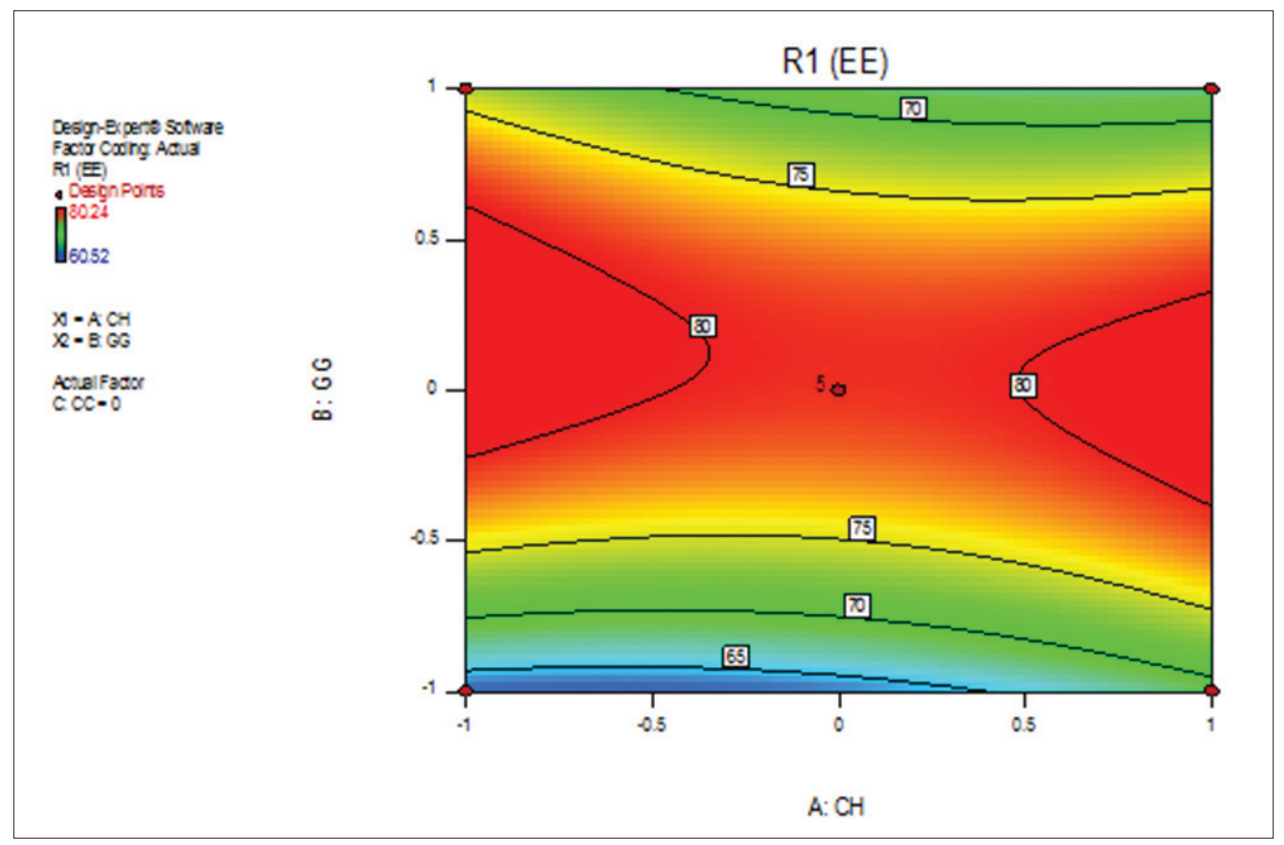

Fig. 14: Contour plot for R1 


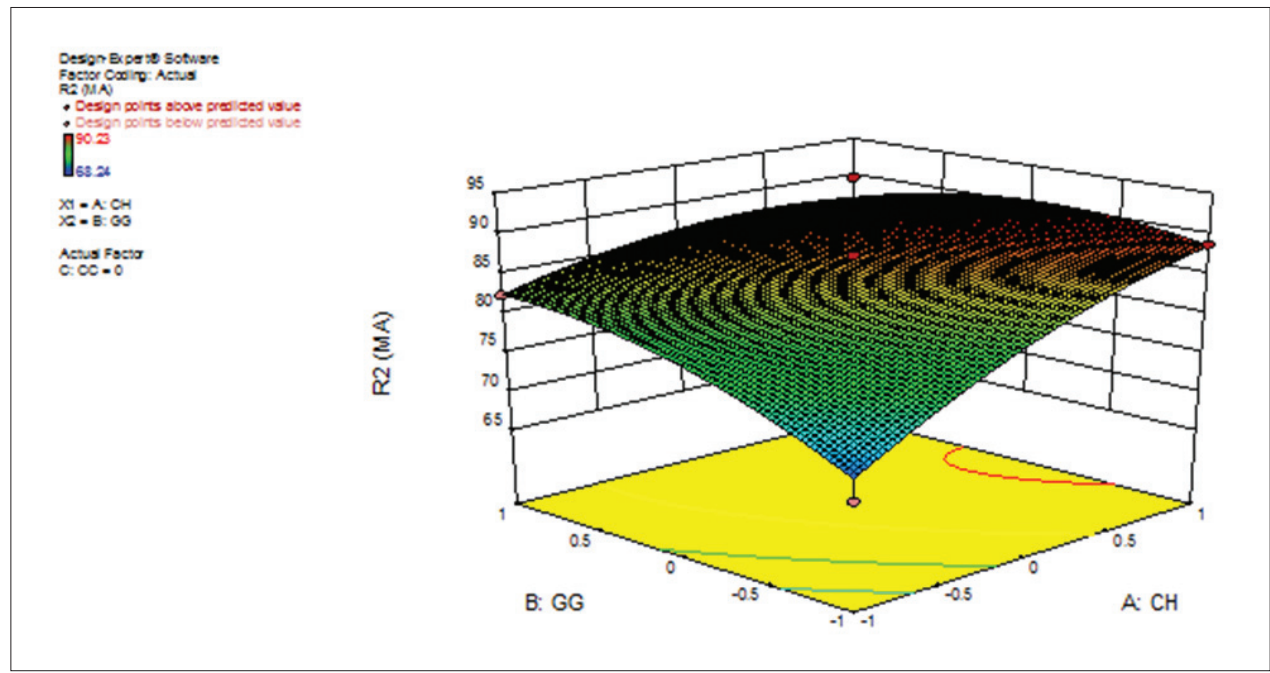

Fig. 15: 3D response curve for $\mathrm{R} 2$

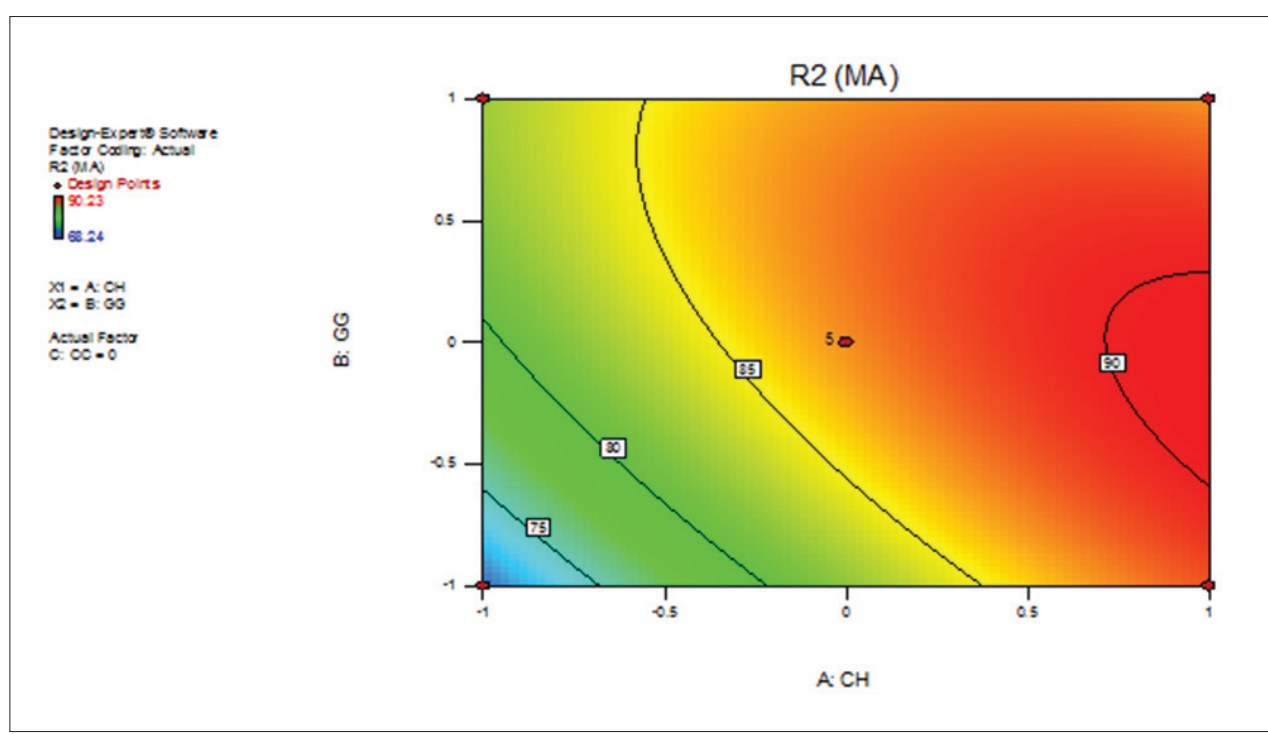

Fig. 16: Contour plot for R2

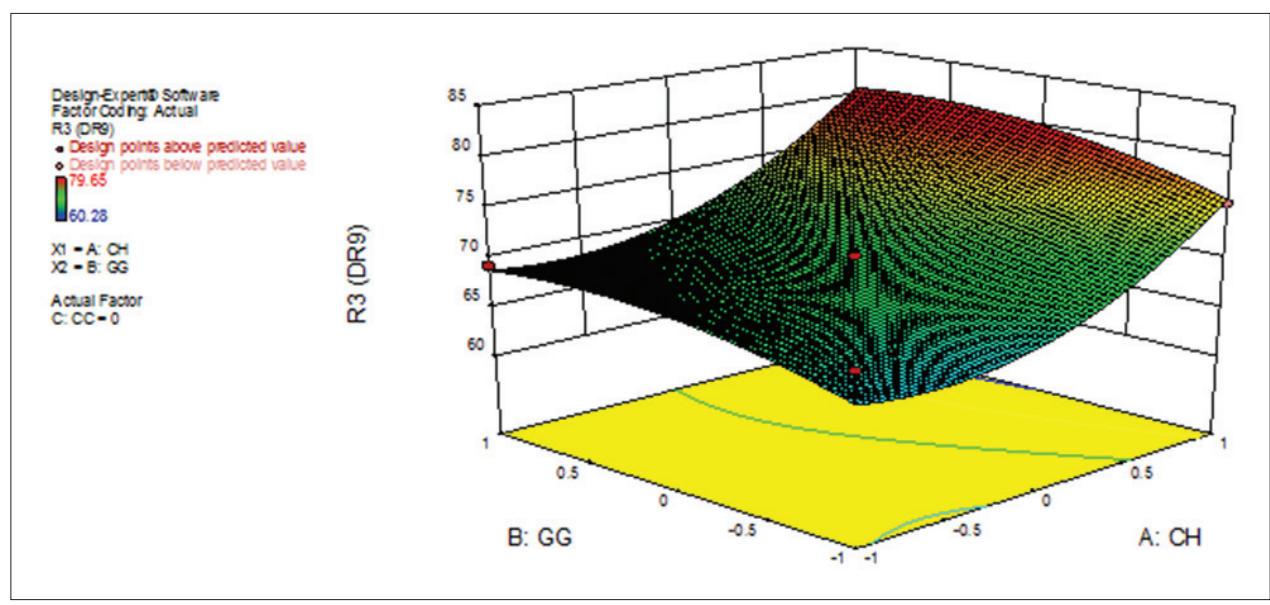

Fig. 17: 3D response curve for $\mathrm{R} 3$

that the contribution of (A, B and C) is significant to model term. The values obtained for main effects of the independent variables from equation indicate that chitosan (A) at high level (1) have a positive effect on the response R5 (drug release at $18 \mathrm{hr}$ ). From the figure 19 and 20 of the response curve of drug release at $9 \mathrm{hr}$ for multiparticulate, it is observed that high (1) concentration of chitosan (A) releases the drug 


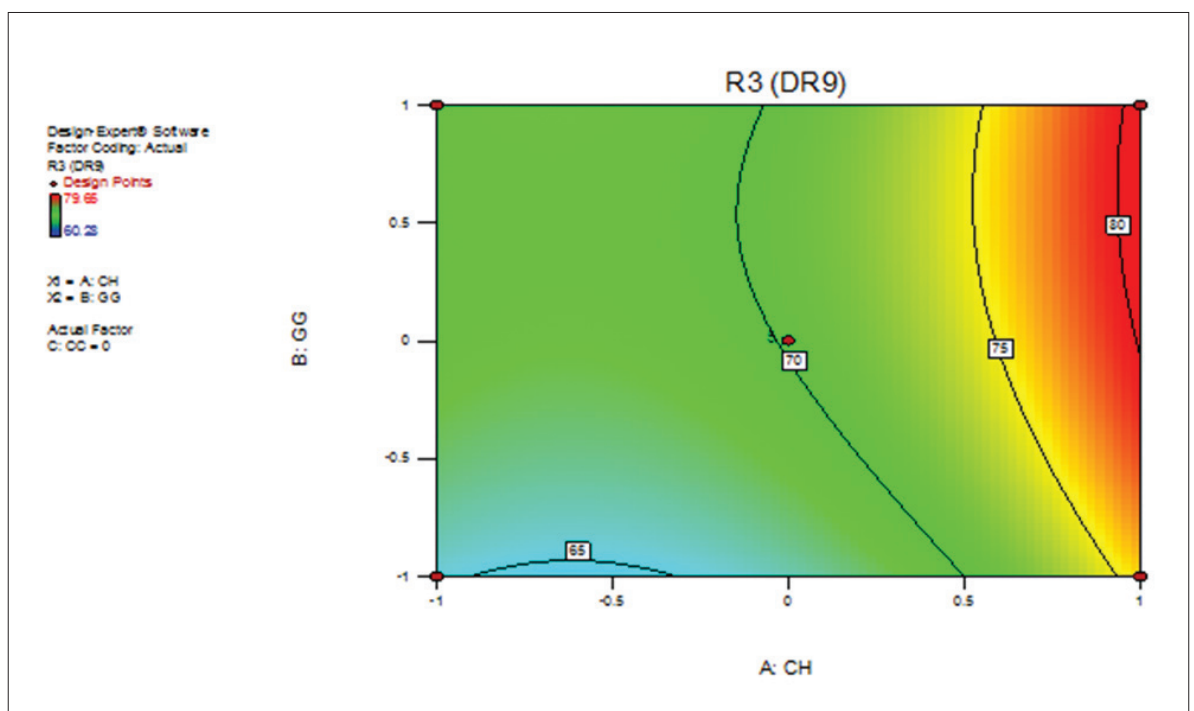

Fig. 18: Contour plot for R3

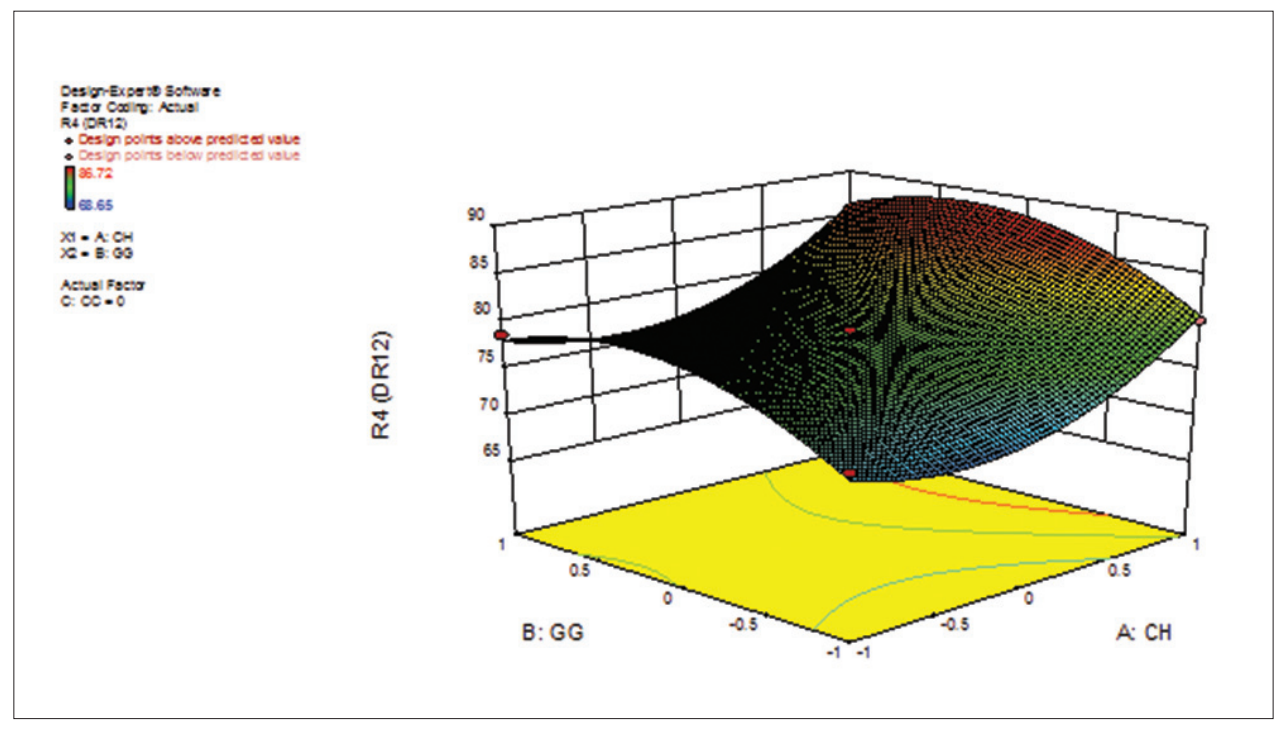

Fig. 19: 3D response curve for $R 4$

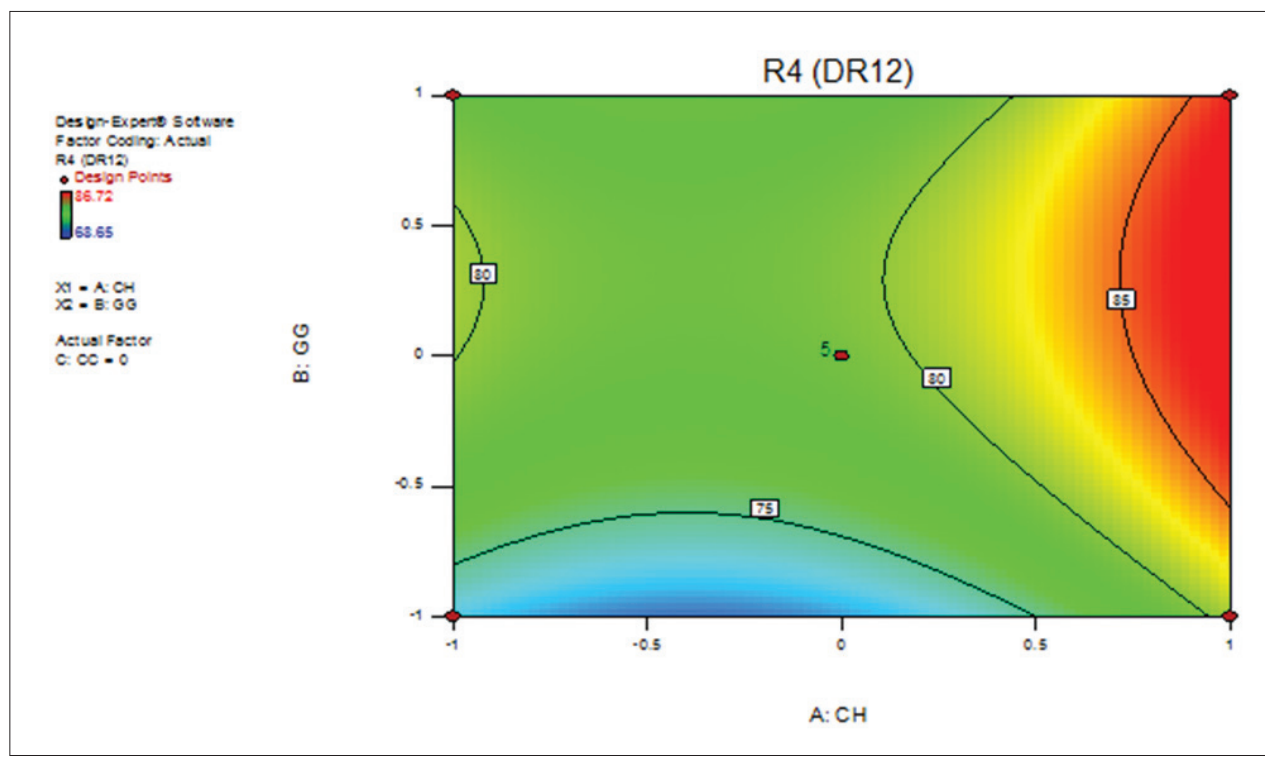

Fig. 20: Contour plot for R4 
at $18 \mathrm{hr}$ significantly. From equation, they indicate that concentrations of guar gum (B) at medium level (0) are effective for response R5 (drug release at $18 \mathrm{hr}$ ). On the other hand, the coat composition at a low level $(-1)$ is sufficient to reach the multiparticulate to colon (Figs. 21 and 22).

For response R6 (drug release at $24 \mathrm{hr}$ ), the model F value of 17.51 implies the model is significant. There is only a $0.05 \%$ chance that a "Model $\mathrm{F}$ value" this large could occur due to noise. Values of "p $>\mathrm{F}$ " $<0.0500$ indicate model terms are significant. In this case, $\mathrm{A}, \mathrm{A}++2+-$, and $\mathrm{C}++2+-$ are significant model terms. Values $>0.1000$ indicate the model terms are not significant. If there are many insignificant model terms (not counting those required to support hierarchy), model reduction may improve your model. The "Lack of Fit F value" of 29.61 implies the lack of fit is significant. There is only a $0.34 \%$ chance that a "Lack of Fit F value" this large could occur due to noise. The $\mathrm{p}$ values for response R6 (drug release at $24 \mathrm{hr}$ ) represent that the contribution of (A, B, and C) is significant to model term, and the linear contribution (C) is the nonsignificant model term. The values obtained for main effects of the independent variables from equation indicate that chitosan (A) at high level (1) have a positive effect on the response R6 (drug release at $24 \mathrm{hr}$ ). From the Figure. 19 and 20 of the response curve of drug release at $24 \mathrm{hr}$ for multiparticulate, it is observed that high (1) concentration of chitosan (A) releases the drug at $24 \mathrm{hr}$ significantly. From equation, they indicate that concentrations of guar gum (B) at medium level (0) are effective for response R6 (drug release at $24 \mathrm{hr})$. On the other hand, the coat composition at low level (-1) is sufficient to reach the multiparticulate to colon (Figs. 23 and 24).

\section{Advanced studies on optimized batch of multiparticulates XRD study}

The powder XRD patterns for the pure ciprofloxacin and their polymeric composites are given in Fig. 25. The data obtained for the multiparticulate of ciprofloxacin in terms of the lattice spacing and the relative line intensities. Most of the characteristic lines in the diffraction patterns were generally prominent and sharp. Proper sample preparation helps attain accurate peak positions for qualitative analysis. If the sample surface is irregular or if it is displaced from the focusing circle, peak locations and intensities will vary. All the high-intensity peaks (relative intensity) observed in the XRD pattern of the pure drug ciprofloxacin were compared. The pure drugs were found to show similar XRD patterns as that with the polymeric composites. Identification of a structure from its powdered diffraction pattern is based on the position of peaks and their relative intensities. Each XRD pattern is characterized by the $2 \theta$ and the relative intensities (I/I0) of strongest peaks.

\section{DSC studies of optimized multiparticulates}

The thermograms of the pure drug characteristic, sharp endothermic peak at $288.90^{\circ} \mathrm{C}$ for ciprofloxacin, also the thermogram of physical mixtures
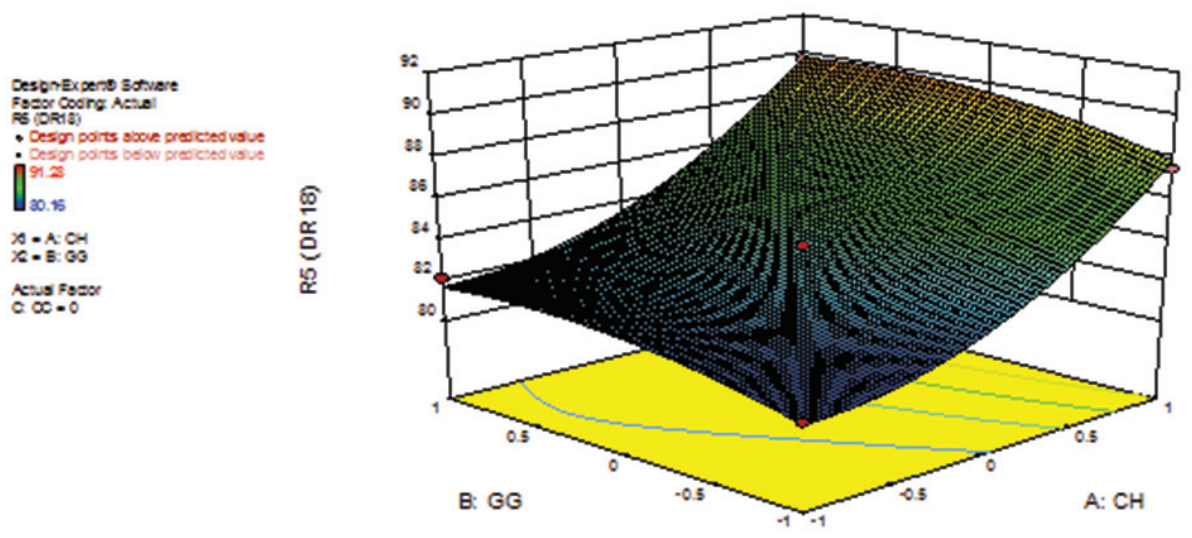

Fig. 21: 3D response curve for $\mathrm{R} 5$

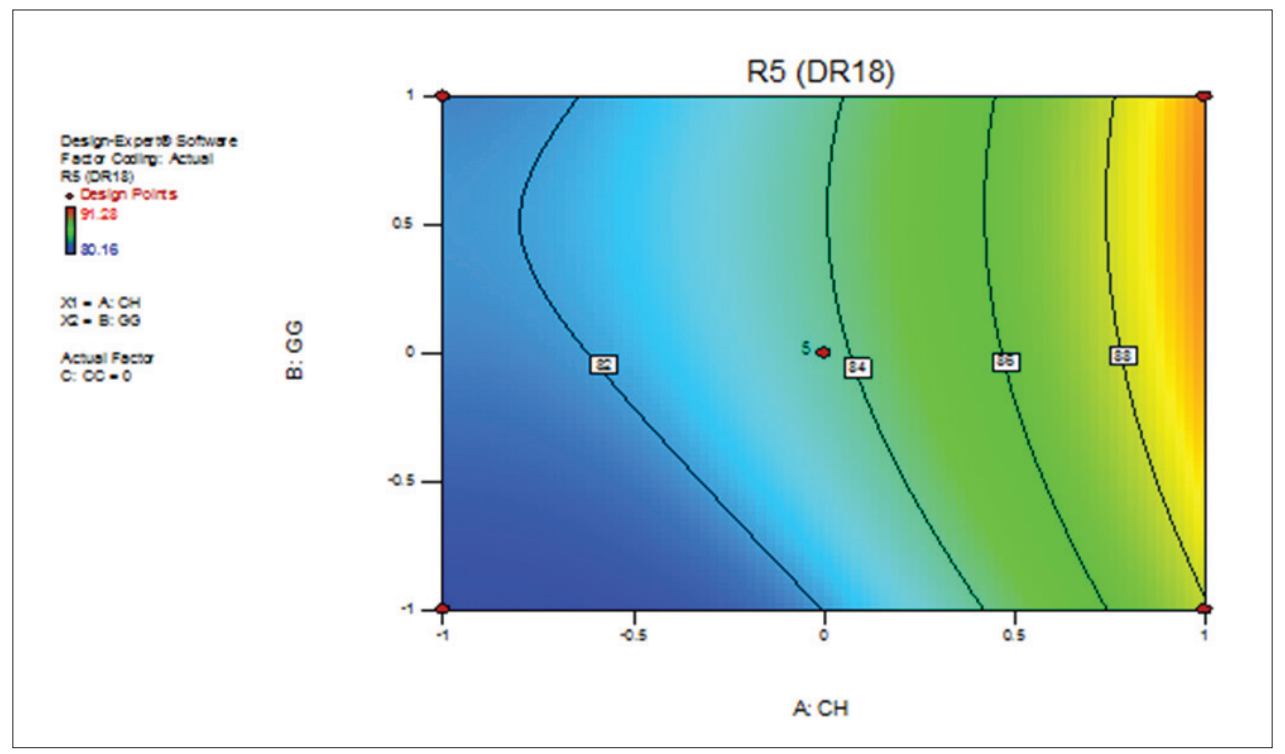

Fig. 22: Contour plot for R5 


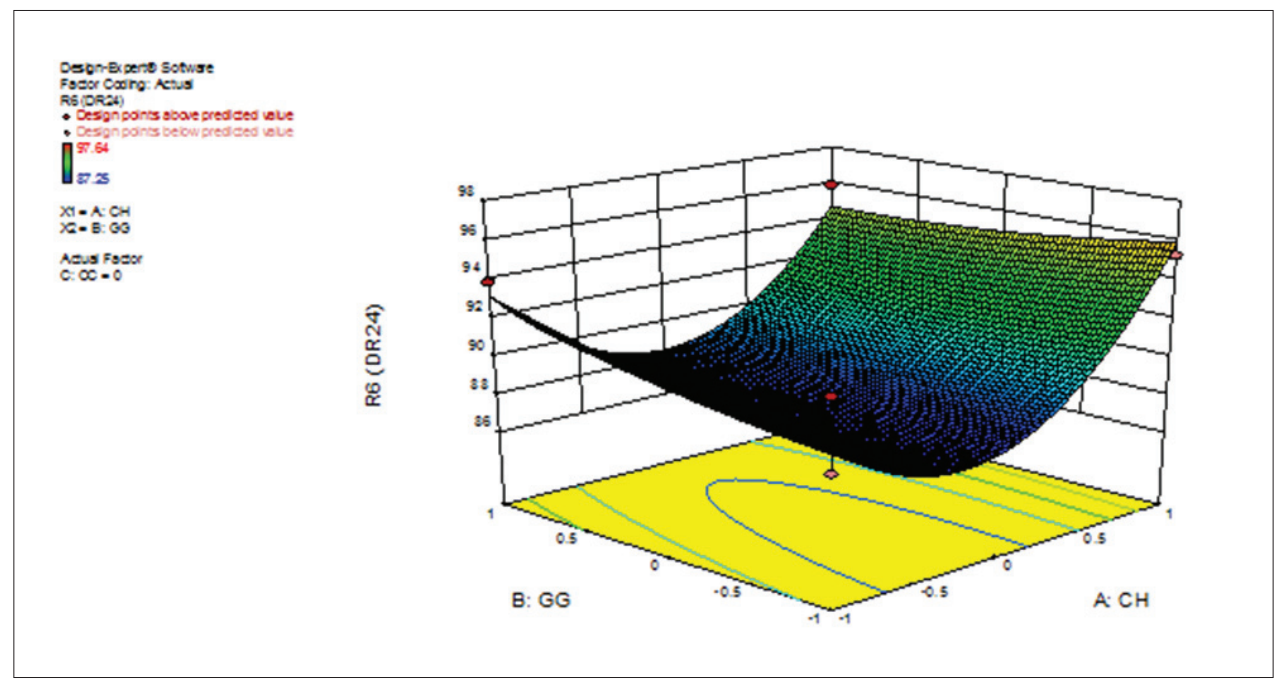

Fig. 23: 3D response curve for $\mathrm{R} 6$

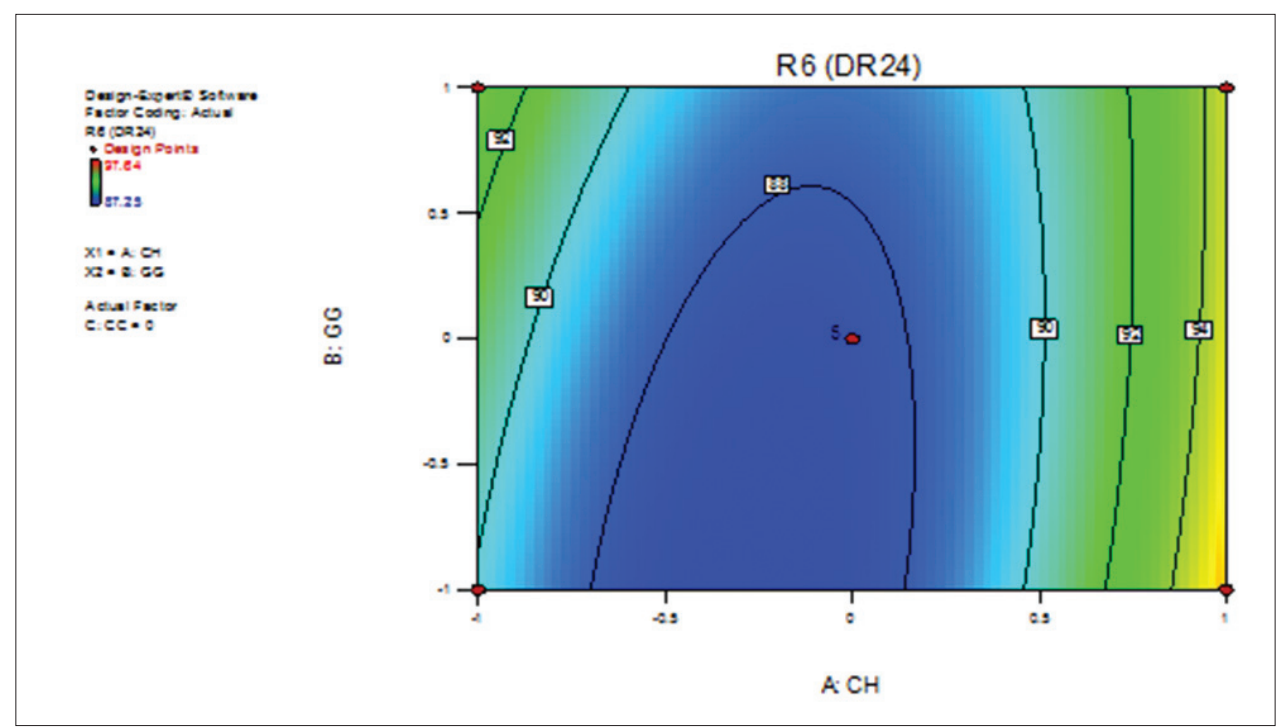

Fig. 24: Contour plot for R6

of optimized formulation shows characteristic, sharp endothermic peaks at $297.81^{\circ} \mathrm{C}$ for physical mixture of ciprofloxacin. This concludes that the peaks were associated with the melting point of the drug and indicates the amorphous nature of the drug. The DSC thermogram of polymers (Figs. 27 and 28), pure drug ciprofloxacin (Fig. 26), and their physical mixture of polymer of optimized batches were shown in the following Fig. 29.

\section{Morphological results with SEM}

Morphology of multiparticulate was examined by SEM. The smooth surface of such multiparticulate as seen by SEM might be due to this complete homogeneity of drug and polymers and coating. The outer surface of the multiparticulate was smooth and dense this is because of coating of mulatiparticulate using coat composition of Eudragit S and L 100, whereas the internal surface was porous. The shell of the multiparticulate also showed some porous structure. It may be caused by the evaporation of the solvent entrapped within the shell of multiparticulate after forming a smooth and dense skin layer. Some of the multiparticulate showed a dented surface structure (Figs. 30-32).

\section{IR interpretations for drug polymer interaction in formulation}

IR spectroscopy was used as means of studying drug-excipients compatibility and confirmed by comparing undisturbed structure of IR spectra of pure ciprofloxacin (Fig. 33), polymers (Figs. 34 and 35), and physical mixture of optimized batch (Fig. 36) which indicated no drugexcipients interaction.

\section{In vivo gamma scintigraphy study}

The gamma scintigraphy study in rat showed that the multiparticulate were intact in the hostile environment of the stomach at 1 and 15 minutes duration, but whenever, they reached to the colonic region they stars degradation due to the presence of anaerobic bacteria present in colon (Fig. 37).

\section{Histopathology evaluation}

During the experimental period (84 days), the inflammatory agent exposed rats (Group II) exhibited a significantly low gain in body weight and growth rate throughout the experimental period as compared to Group I and Group III. To the Group III (multiparticulates containing $250 \mathrm{mg} / \mathrm{kg} /$ day of ciprofloxacin), was administered which shows significantly increased in weight gain when compared with Group II (Table 10).

Histopathological observations of the colon from control group animals Group I showed the normal structure of the villi (Figs. 38 and 39). 


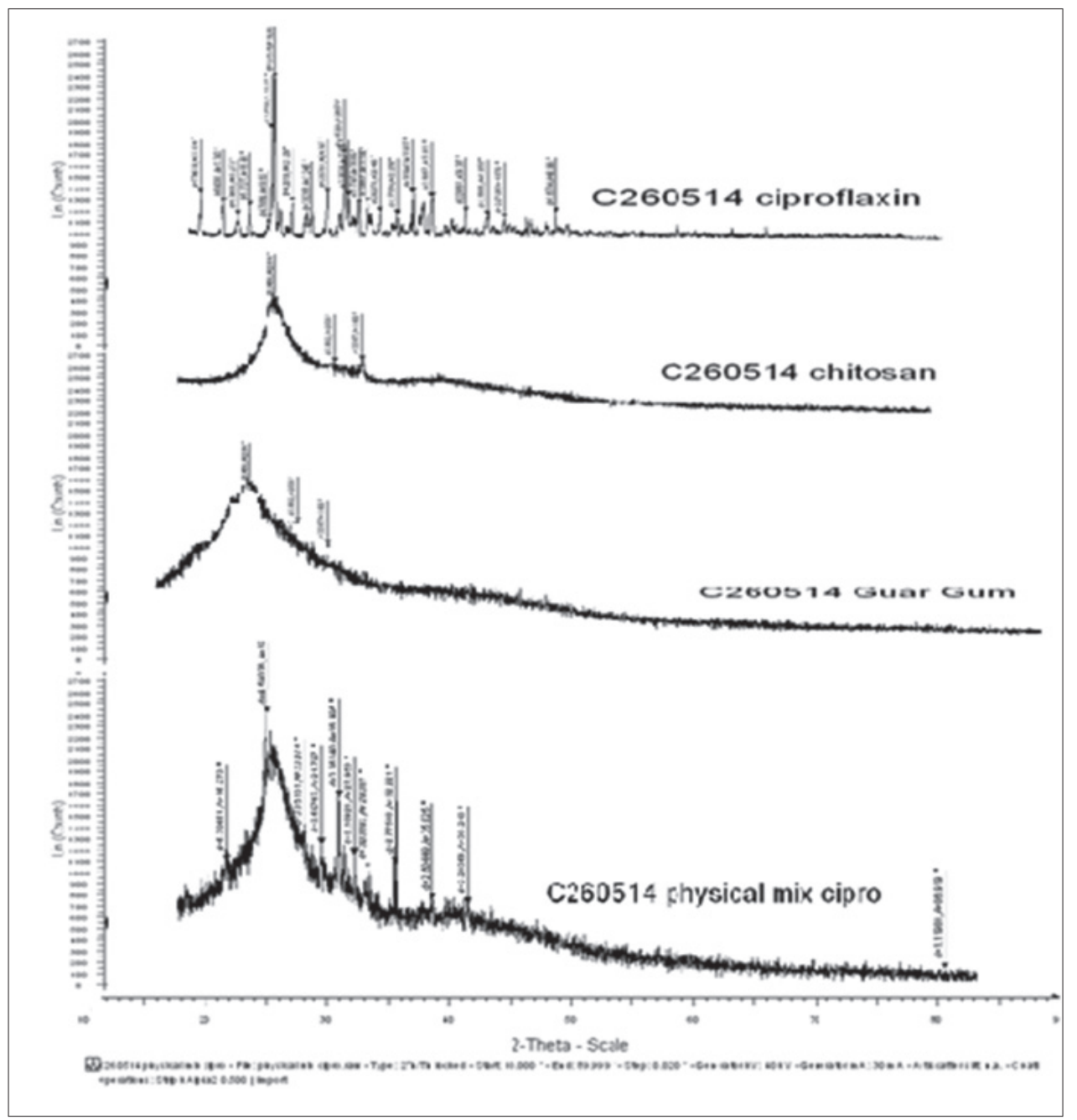

Fig. 25: Comparative graph of ciprofloxacin, chitosan, guar gum, and polymer composite of optimized batch

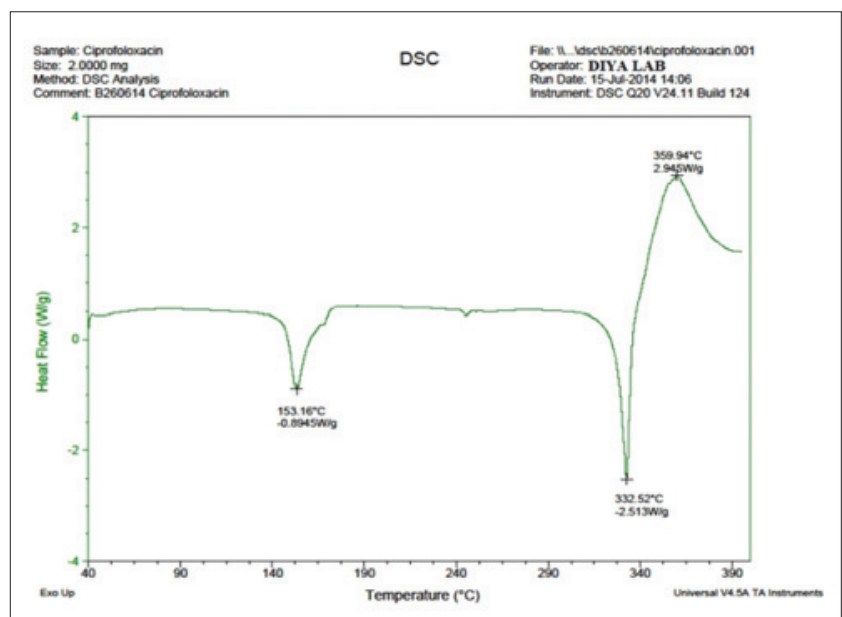

Fig. 26: Differential scanning colorimeter of pure drug ciprofloxacin

2, 4, 6, trinitrobenzene sulfonic acid administered colons showed inflammatory changes as the presence of inflammatory cells in submucosal area and distortion of villi (Group II) (Figs. 40 and 41). Treatment with ciprofloxacin multiparticulate (Group III) has shown reduction in the infiltration of inflammatory cells and villi appeared normal (Fig. 42).

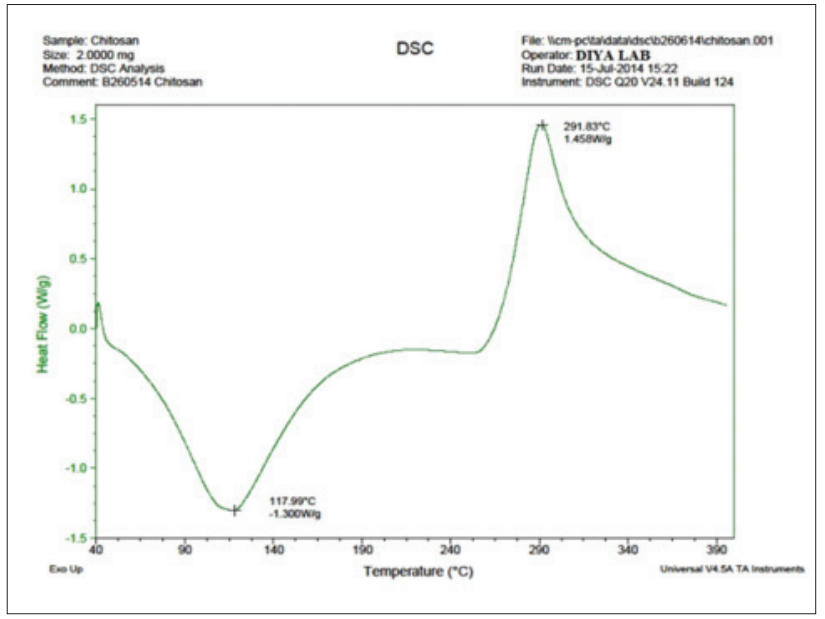

Fig. 27: Differential scanning colorimeter of polymer chitosan

\section{CONCLUSION}

Targeted drug delivery into the colon is highly desirable for local treatment of a variety of bowel diseases such as ulcerative colitis, Crohn's disease, amebiosis, colonic cancer, local treatment of colonic pathologies, and systemic delivery of protein and peptide drugs. Specifically, mucoadhesive multiparticulate systems appear to be an exploitable delivery system for colon release of drugs, and hence, we have selected this topic for our 


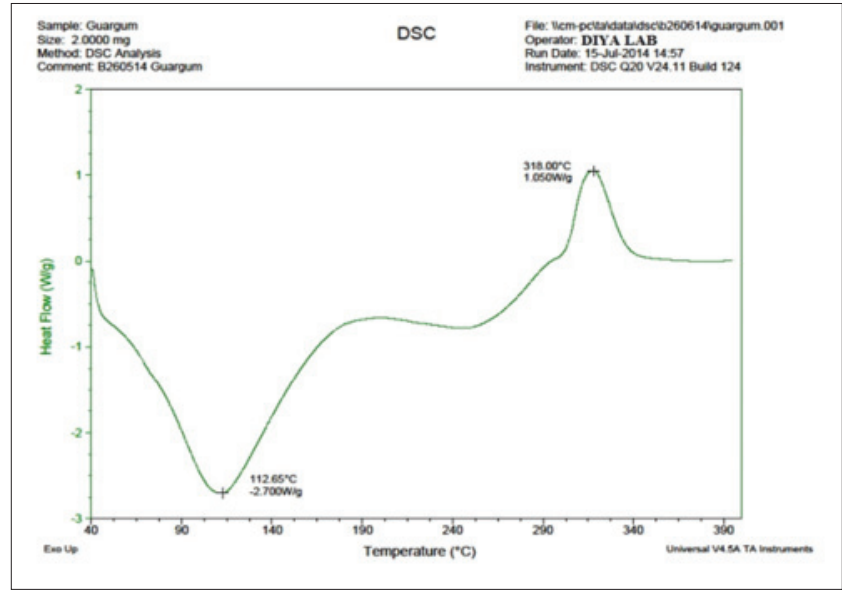

Fig. 28: Differential scanning colorimeter of polymer guar gum

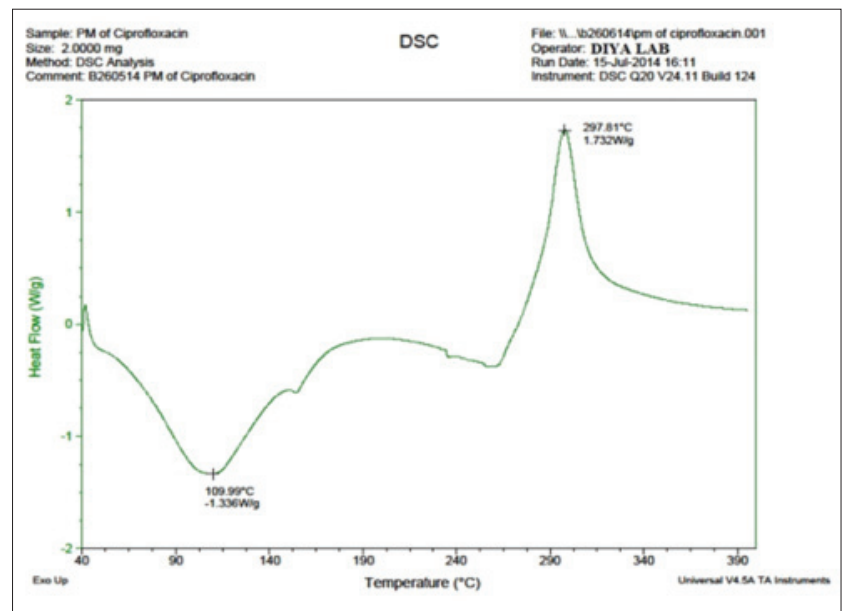

Fig. 29: Differential scanning colorimeter of optimized batch of ciprofloxacin

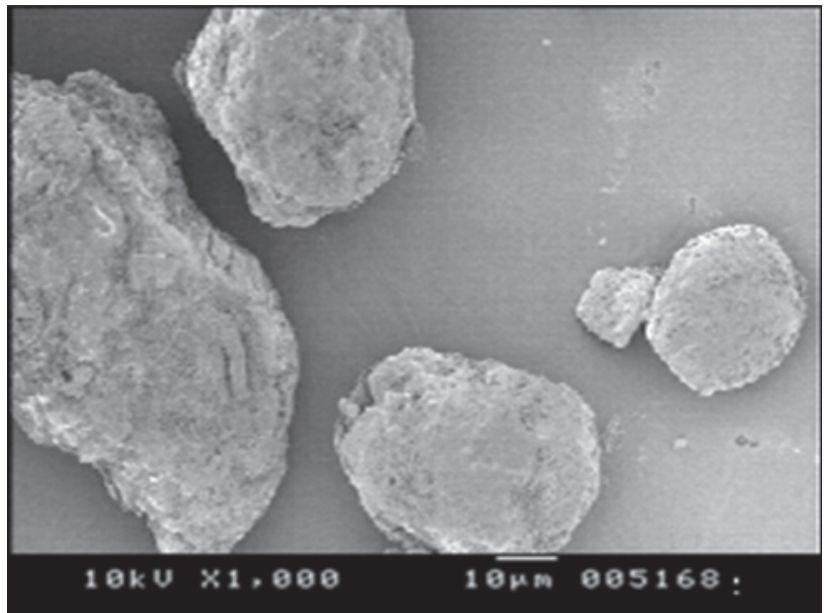

Fig. 30: Scanning electron microscopy of multiparticulate with coating

research. For this, we have selected antibiotic agent ciprofloxacin. These categories of drug generally used to cure diseases related to colon. To prepare mucoadhesive colon targeted multiparticulate system, we have used natural polymers such as chitosan and guar gum together with Eudragit S and L 100 for coating of multiparticulate. The drugs and excipient were subjected to compatibility testing before formulation,

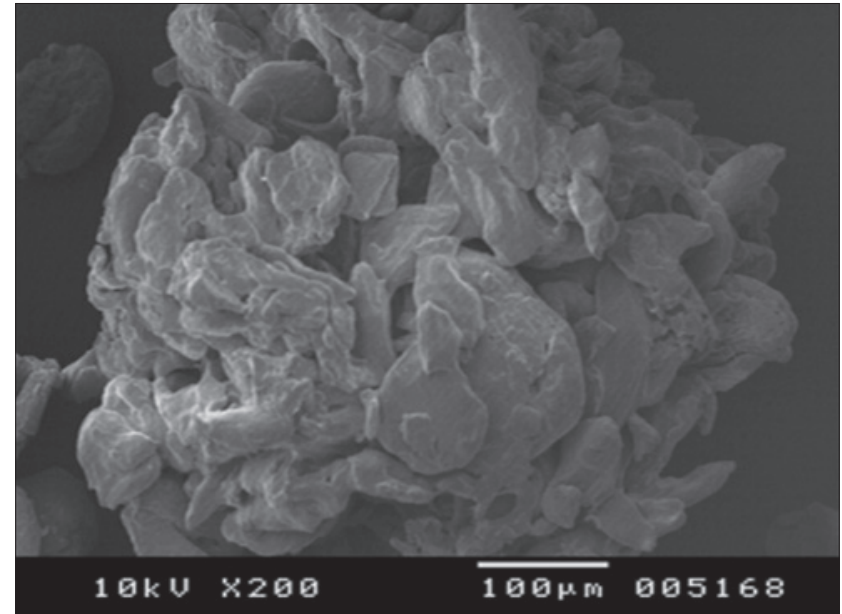

Fig. 31: Scanning electron microscopy of multiparticulate without coating

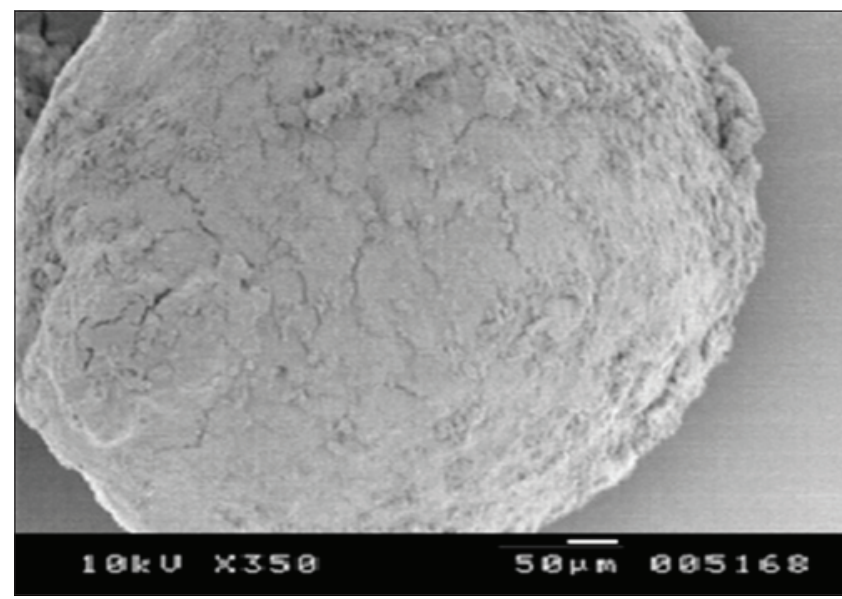

Fig. 32: Scanning electron microscopy of optimized batch of ciprofloxacin

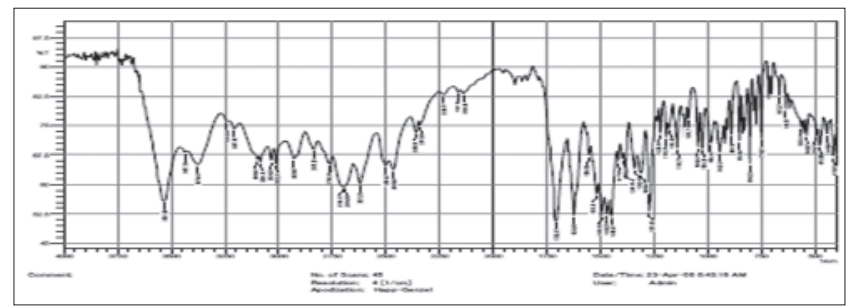

Fig. 33: IR of pure drug ciprofloxacin

i.e., IR, DSC, and XRD. The result of drug excipient compatibility testing reveals that there is no sign of incompatibility in peaks for respective analysis.

The preliminary trial batches were prepared and evaluated, out of which, for C3a, C5a, C3b, and C5b shows good entrapment efficiency, swelling index, ex vivo mucoadhesion, and in vitro drug release than other formulation. Factorial batches were also prepared using "Design Expert Software," and formulations were also evaluated for same as like for preliminary trials. For formulated factorial batches, of ciprofloxacin C4 batch shows good entrapment efficiency, swelling index, ex vivo mucoadhesion, and in vitro drug release and was considered as an optimized formulation and further subjected to advanced studies such as SEM, in vivo evaluation (gamma scintigraphy), and histopathological study. The results of 


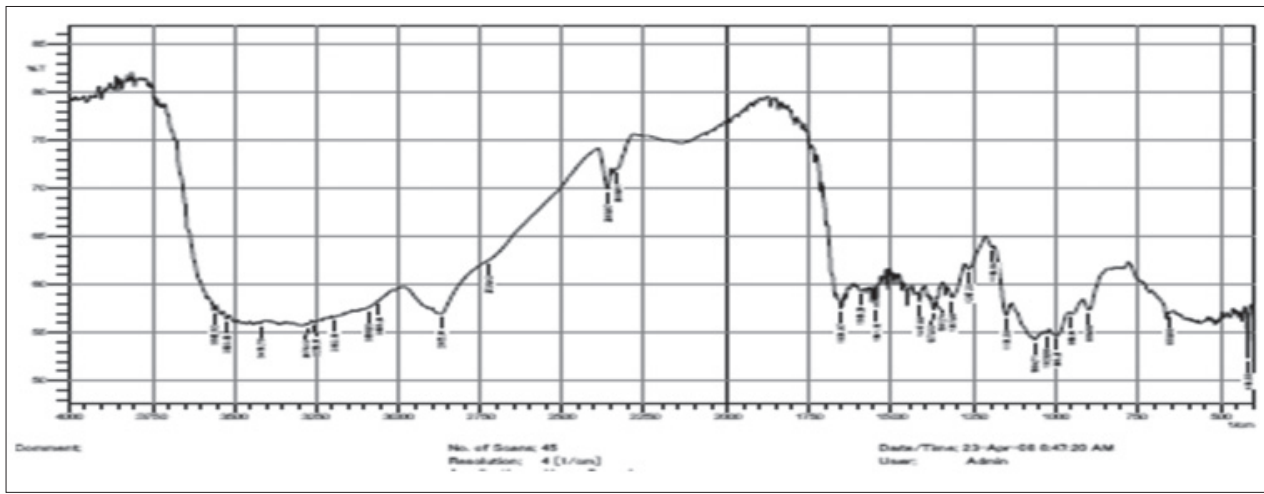

Fig. 34: IR of polymer chitosan

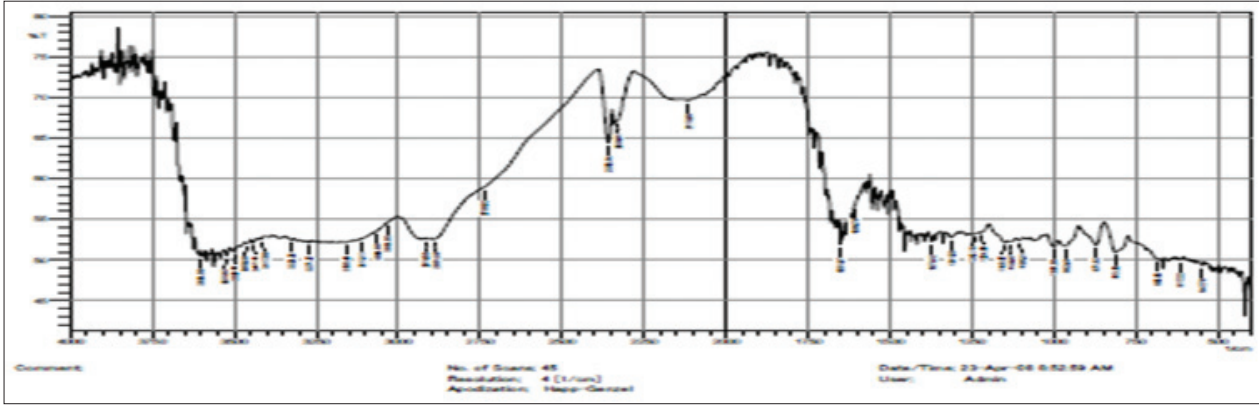

Fig. 35: IR of polymer guar gum

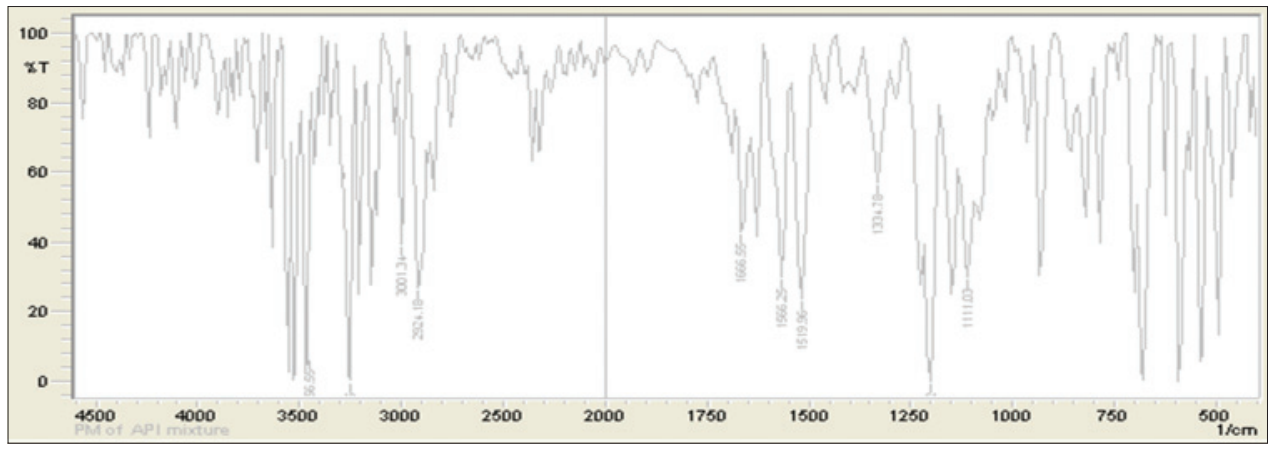

Fig. 36: Physical mixture of optimized batch of ciprofloxacin

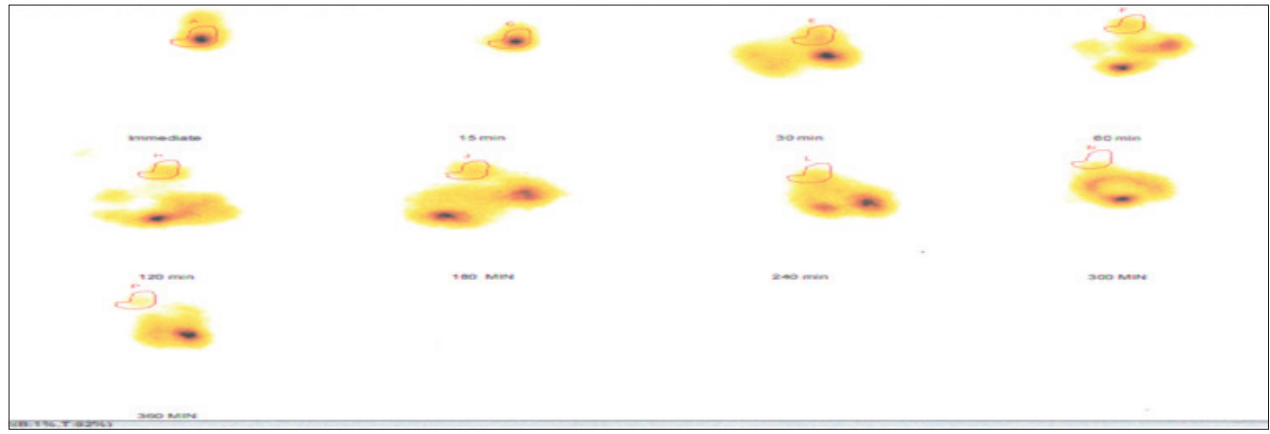

Fig. 37: In vivo gamma scintigraphy on Wistar male rat male rat using multiparticulate without drug

the study clearly indicate that there is a great potential in delivery of ciprofloxacin to the colonic region. The study showed that the manipulation of polymer concentration and coat composition influence particle size of multiparticulate, flow property, drug release profile, etc. From the above study, it concluded that high concentration of chitosan together with guar gum retard the drug release, may be due to the cross-linking of chitosan which did not disintegrate under the influence of colon enzymes and also coating with Eudragit S and L 100 composition prevents its release in GIT and helps to target the drug in colon. Formulation C4 for ciprofloxacin was the best formulation for controlling the drug release to the colon. The efficiency of ciprofloxacin as a nonsteroidal anti-inflammatory drug 


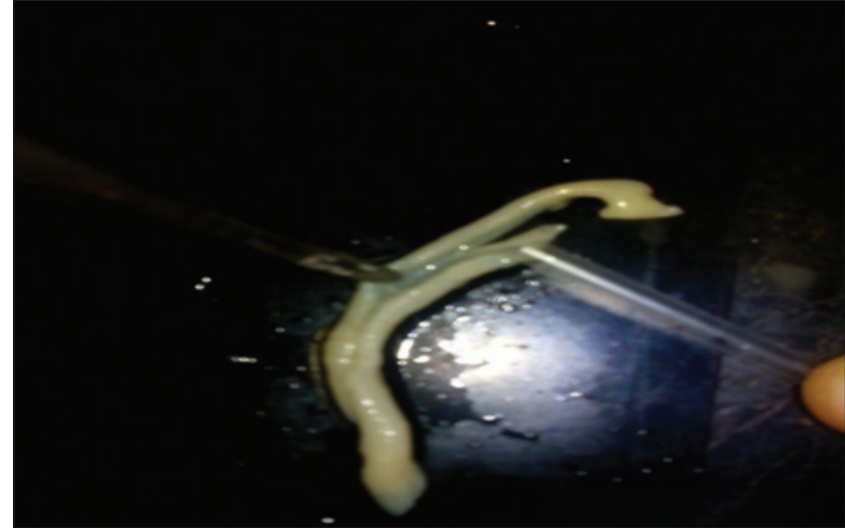

Fig. 38: Photograph of colon (Group I)

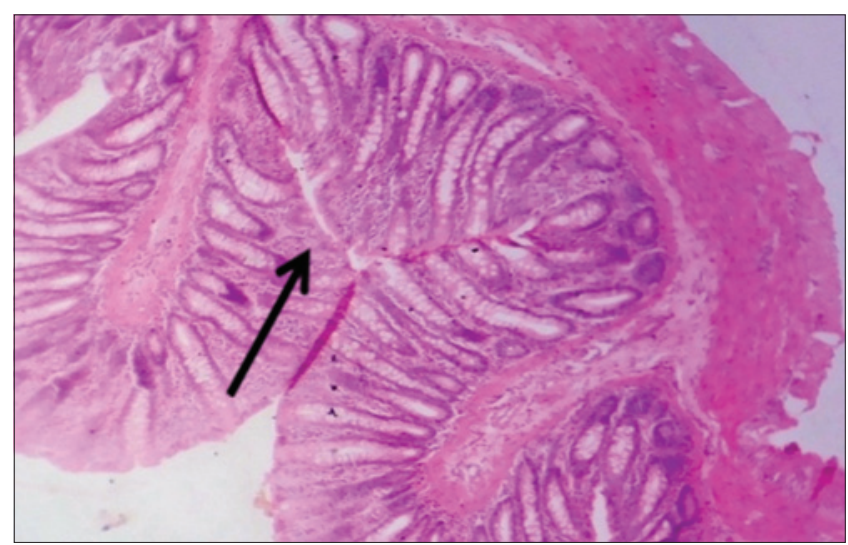

Fig. 39: Group I show normal villi

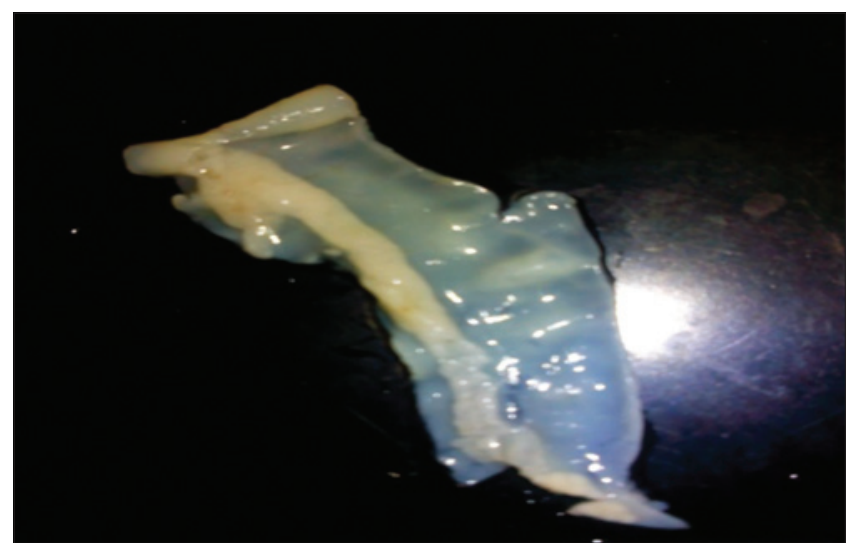

Fig. 40: Photograph of colon (Group II)

was also evaluated successfully with $2,4,6$, trinitrobenzene sulfonic acid colitis in rat model. The formulation $\mathrm{C} 4$ confirmed to serve as a new drug delivery system to treat inflammatory bowel disease.

Gamma scintigraphy and histological study of optimized formulation C4 for ciprofloxacin showed that the formulation can specifically deliver the drug to the site of action; the animals treated with this formulation had an improvement in pathology and may be useful for the treatment of inflammatory bowel disease and colon cancer.

\section{ACKNOWLEDGMENT}

Author wish to express their sincere thank to Dr. P.K.Puranik, Professor, Department of Pharmaceutical Sciences RTM Nagpur University, Maharashtra, India, for their valuable guidance time to time during

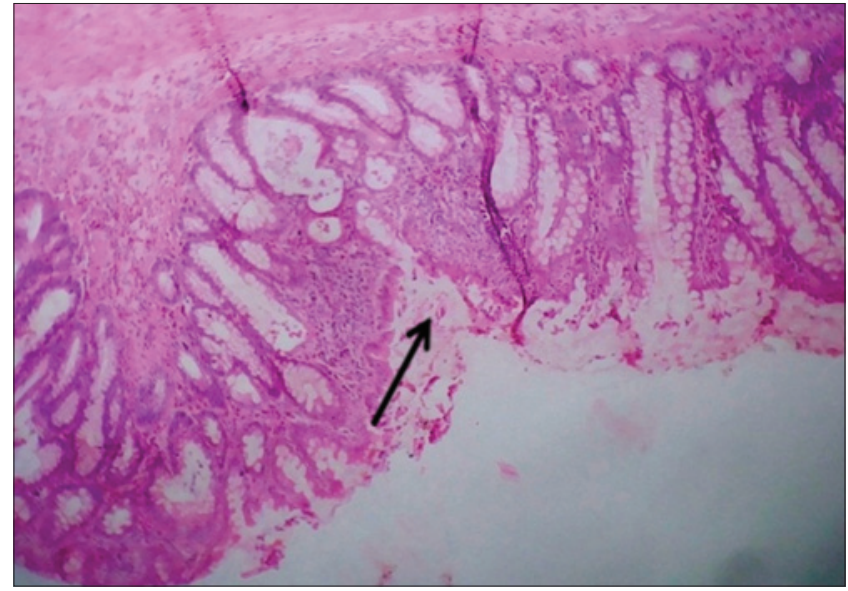

Fig. 41: 2, 4, 6 trinitrobenzene sulfonic acid-induced inflammations (Group II)

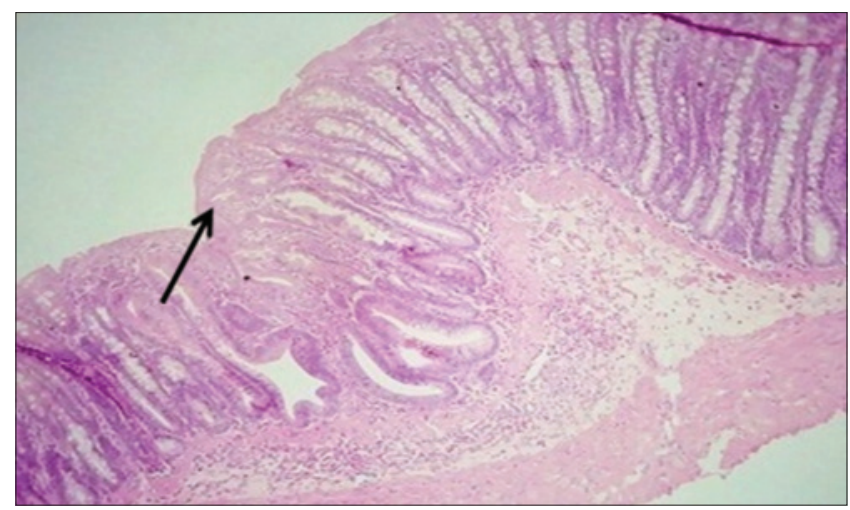

Fig. 42: Ciprofloxacin (Group III)

the commencement of the research work. Furthermore, the author expresses their great gratitude towards Dr. T.M. Kalyankarr, Swami Ramanand Teerth Marathwada University, Nanded, Maharashtra, India, for their constant encouragement and support.

\section{REFERENCES}

1. Mura C, Nacher A, Merino V, Merino M, Carda C, Ruiz A, et al $\mathrm{N}$-Succinyl-Chitosan systems for 5-aminosalicylic acid colon delivery: In vivo study with TNBS-induced colitis model in rats. Int J Pharm 2011;416(1):145-54.

2. Philip AK, Dabas S, Pathak K. Optimized prodrug approach: A means for achieving enhanced anti-inflammatory potential in experimentally induced colitis. J Drug Target 2009;17(3):235-241

3. Oluwatoyin AO, John TF. In vitro evaluation of khaya and albizia gums as compression coating for drug targeting to the colon. J Pharm Pharmacol 2005;57(2):63-168.

4. Akala EO, Elekwachi O, Chase V, Johnson H, Marjorie L, Scott K. Organic redox initiated polymerization process for the fabrication of hydrogel for colon specific drug delivery. Drug Dev Ind Pharm 2003;29(4):375-86.

5. Akhgari A, Garekani H, Sadeghi F, Azimaie M. Statistical optimization of indomethacin pellets coated with $\mathrm{pH}$-dependent methacrylic polymers for possible colonic drug delivery. Int J Pharm 2005;305(1-2):22-30.

6. Annadurai G, Sheeja RY. Use of Box-Behnken design of experiments for the adsorption of Verofix red using biopolymer. Bioprocess Eng 1998; 18:463-6.

7. Rangari NT, Puranik PK. Development of multiparticulate formulation and evaluation of colon targeted drug delivery system of Ketoprofen: In vivo study with induced colitis model in rats and gamma scintigraphy. Asian J Pharm Clin 2016;9:234-52.

8. Shendge RS, Sayyad FJ. Statistical optimization of budesonide pellets coated with Eudragit polymer for possiblecolonic drug delivery. Asian 
J Pharm Clin 2012;5:215-24.

9. Martina P, Anton C. The dimethylhydrazine induced colorectal tumours in rat-experimental colorectal carcinogenesis. Radiol Oncol 2005;39:61-70.

10. Motwani SK, Chopra S, Talegaonkar S, Kohli K, Ahmad FJ, Khar RK. Chitosan-sodium alginate nanoparticles as submicroscopic reservoirs for ocular delivery: Formulation, optimization and in vitro characterization. Eur J Pharm Biopharm 2007;53:235-43.
11. Singh SK, Dodge J, Durrani MJ, Khan MA. Optimization and characterization of controlled release pellets coated with an experimental latex: I. Anionic drug. Int J Pharm 1995;125:243-55.

12. Chourasia MK, Jain S K. Pharmaceutical approaches to colon targeted drug delivery systems. J Pharm Sci 2003;6(1):33-66.

13. Salve PS. Development and in vitro evaluation colon targeted drug delivery system using natural gums. Asian J Pharm Res 2011;1:91-101. 